Session 2003-2484

\title{
Issues Encountered with Students using Process Simulators
}

\author{
Mariano J Savelski and Robert P. Hesketh \\ Department of Chemical Engineering \\ Rowan University \\ 201 Mullica Hill Road \\ Glassboro, New Jersey 08028-1701
}

\begin{abstract}
Process Simulators has become an indispensable tool for design and retrofit of refineries and petrochemical plants. Originally created for the commodity industry, the advantages provided by these tools have made them also an attractive option for other industrial application such as pharmaceutical and specialty chemicals. Software companies are constantly increasing the capability of simulators to include novel technology and expand their applications market.

In the last twenty years simulators have also become much more user friendly and have been expanded to incorporate equipment design and costing tools. As a result, Chemical Engineering programs throughout the nation started using them for a variety of reasons. Some professors see process simulators as a must-do-must-teach so students are familiarized with their use by the time they graduate. In this case process simulators are generally introduced during the senior design sequence or simply in plant design courses. Others have found in process simulators a valuable teaching aid as well.

At Rowan we introduce process simulators starting at freshmen year and use them as a pedagogical tool in several courses throughout the curriculum. This process has allowed us to develop valuable examples and case studies to show students of the importance of reality checks and the immediate consequences of "blindly" trusting the process simulators results. Examples applied to system thermodynamics, distillation and reactor design will be shown.
\end{abstract}

\section{Introduction}

Process simulators are becoming a basic tool in chemical engineering programs. Senior level design projects typically involve the use of either a commercial simulator or an academic simulator such as ASPENPLUS, ChemCAD, ChemShare, FLOWTRAN, HYSYS, and PROII w/PROVISION. Many design textbooks are now including exercises specifically prepared for a particular simulator. For example the text by Seider, Seader and Lewin (1999) ${ }^{1}$ has examples written for use with ASPEN Plus, HYSYS, GAMS ${ }^{2}$ and DYNAPLUS ${ }^{3}$. Professor Lewin has prepared a new CD-ROM version of this courseware giving interactive selfpaced tutorials on the use of HYSYS and ASPEN PLUS throughout the curriculum. ${ }^{45}$

In the past, most chemical engineering programs have seen process simulation as a tool to be taught and used solely in senior design courses. Lately, the chemical engineering community has seen a strong movement towards the vertical integration of design throughout the 
curriculum. ${ }^{6,7,8,9}$ Some of these initiatives are driven by the new ABET criteria. ${ }^{10}$ This integration could be highly enhanced by an early introduction to process simulation.

Process simulation can also be used in lower level courses as a pedagogical aid. The thermodynamics and separations areas have a lot to gain from simulation packages. One of the advantages of process simulation software is that it enables the instructor to present information in an inductive manner. For example, in a course on equilibrium staged operations one of the concepts a student must learn is the optimum feed location. Standard texts such as Wankat $(1988)^{11}$ present these concepts in a deductive manner.

Some courses in chemical engineering, such as process dynamics and control and process optimization, are computer intensive and can benefit from dynamic process simulators and other software packages. Henson and Zhang $(2000)^{12}$ present an example problem in which HYSYS.Plant, a commercial dynamic simulator, is used in the process control course. The process features the production of ethylene glycol in a CSTR and the purification of the product through distillation. The authors use this simple process to illustrate concepts such as feedback control and open-loop dynamics. Clough $(2000)^{13}$ presents a good overview of the usage of dynamic simulation in teaching plantwide control strategies.

A potential pedagogical drawback to simulation packages such as HYSYS and ASPEN is that it might be possible for students to successfully construct and use models without really

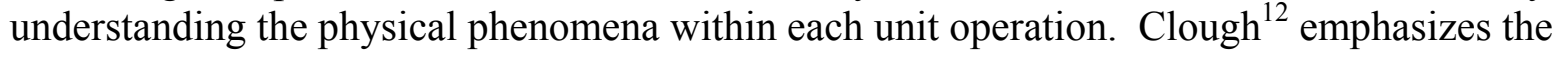
difference between "students using vs. student creating simulations". Care must be taken to insure that simulation enhances student understanding, rather than providing a crutch to allow them to solve problems with only a surface understanding of the processes they are modeling. This concern about process simulators motivated the development of the phenomenological modeling package ModelLA. ${ }^{14}$ This package allows the user to declare whatever physical and chemical phenomena are operative in a process or part of a process. Examples include choosing a specific model for the finite rate of interphase transport or the species behavior of multi-phase equilibrium situations. One uses engineering science in a user-selected hierarchical sequence of modeling decisions.

At Rowan University we have several examples in which students have encountered problems using simulators. We believe that the following examples are illustrative of problems that students should be shown in using simulators. Examples from the reaction engineering course and the plant design course will be given.

\section{Chemical Reaction Engineering}

In the current chemical reaction engineering course most students are familiar with ODE solvers found in POLYMATH or MatLab. The philosophy given by Fogler ${ }^{15}$ is to have the students use the mole, momentum and energy balances appropriate for a given reactor type. In this manner a fairly detailed model of industrial reactors can be developed for design projects ${ }^{16}$. Using POLYMATH or MatLab a student can easily see the equations used to model the reactor. In modern process simulators there are several reactors that can be used. For example in HYSYS 2.2 there are the two ideal reactor models of a CSTR and a PFR. The CSTR model is a standard algebraic model that has been in simulation packages for a number of years. The ODE's of the PFR are a recent addition to simulation packages and are solved by dividing the volume into small segments and finding a sequential solution for each volume element. In these more recent models, these reactors not only include energy balances, but pressure drop 
calculations are a standard feature for packed bed reactors. Table 8 summarizes the most significant modeling equations and approaches for different types of reactors.

With the above set of reactions, chemical reaction engineering courses can easily use the process simulator. Simulation can be integrated throughout the course and used in parallel with the textbook, or it can be introduced in the latter stages of the course, after the students have developed proficiency in modeling these processes by hand. As mentioned in the discussion section, the primary dilemma that the professor will face is how to insure that the simulator is used to help teach the material, rather than giving students a way to complete the assignment without learning the material. Taking care that assignments require synthesis, analysis and evaluation as well as simple reporting of numerical results will help in this regard. Requiring students to do chosen calculations by hand will insure that they understand what the simulator is actually doing. One can always select chemical compounds that are not present in the simulator database for some examples to insure that these are done by hand.

The objectives of using simulators in chemical reaction engineering are the following:

- Introduce engineering design principles

- Integrate lecture material into a semester project

- Excite students about engineering through actual chemical reactions

- Provide a unifying theme for the course

- Introduce Process Simulation - Reactors

To introduce simulators into reaction engineering the following tutorials have been prepared using the production of styrene as an example Ethylbenzene $\Leftrightarrow$ Styrene + Hydrogen:

$$
\mathrm{C}_{6} \mathrm{H}_{5}-\mathrm{C}_{2} \mathrm{H}_{5} \Leftrightarrow \mathrm{C}_{6} \mathrm{H}_{5}-\mathrm{CH}=\mathrm{CH}_{2}+\mathrm{H}_{2}
$$

- Styrene Reactor Simulation - Inductive Method

- Conversion Reactor Tutorial - Styrene

- Kinetic Reactor Tutorial - Styrene

- Pressure Drop with Catalytic Rates - Styrene

- Reaction Rates which include the Equilibrium Constant

- Multiple Reactions

These tutorials are in adobe pdf format and are located at $\bullet$ http://engineering.rowan.edu/ hesketh/0906316/indexhomework.html An example of the tutorial on problems encountered with equilibrium constants is given below.

\section{Chemical Process Component Design}

In the first semester of their senior year, students are once again introduced to process simulation in Chemical Process Component Design. This is a four credit hour course that teaches the principles of basic engineering design. The class is structured to have a double period devoted for a hands-on simulation exercise every Monday morning throughout the entire fall semester.. By the time the undergraduates reach their senior fall semester they have had several classes in which process simulators are used for instructional purposes. These computer models are designed to complement the pedagogical objectives set for this course.

Students are usually given a short write up containing the problem statement and the required items to report. The students work on the exercise during the lab period assisted by a faculty member and then they submit the requested report at the end of the session. The level of difficulty of these exercises increases as the semester progresses. Each year the lab modules are

Proceedings of the 2002 American Society for Engineering Education Annual Conference \& Exposition Copyright C 2002, American Society for Engineering Education 
modified and updated as needed. In some cases the modifications are linked to a different approach in the topics covered or simply to accommodate for changes in software versions. A list of the modules used in the Fall 2002 follows. The actual writeups are available on line every fall semester at http://sun00.rowan.edu/ savelski/welcome1.htm

$\begin{array}{ll}\text { Lab I: } & \text { Thermodynamics and Simulation } \\ \text { Lab II: } & \text { Distillation: Shortcut methods } \\ \text { Lab III: } & \text { Absorption/Stripping } \\ \text { Lab IV: } & \text { Distillation: Multicomponent systems. } \\ \text { Lab V: } & \text { Shell and Tube Heat Exchangers } \\ \text { Lab VI: } & \text { Piping, pumping and control valves } \\ \text { Lab VIII: } & \text { Overall Plant Simulation } \\ \text { Lab IX: } & \text { Chemical Plant Optimization }\end{array}$

In the first lab we discuss the importance of choosing the appropriate thermodynamic package. Several exercise are proposed in which students can compare the results of using the correct or the incorrect property package. When discussing multicomponent distillation we show the students a higher level of complexity in choosing the proper thermodynamic properties, in this case, the values for the binary interaction coefficient for a system containing benzene, cyclohexane, hydrogen and methane. The first part of this lab consists on the simulation of the production of cyclohexane from the reaction between benzene and hydrogen. After the simulation has been set up we request the students to install a distillation column to obtain the cyclohexane, desired product, to a given purity. This exercise could be very frustrating for the student since the default binary coefficient for the pair benzene/cyclohexane are not the correct experimental values but internally estimated values. The column does not usually converge but when it does, it renders a useless design with abnormalities such as reflux ratios in the order of hundred of thousands. The correct regressed experimental values for the binary coefficients are then provided to the students and the distillations are run once again. The students realize that although they have selected the correct thermodynamic package for the given system, some of the default values were incorrect and as a result a faulty design was obtained. This type of exercises helps the design instructor to convey the importance of performing reality checks and critical analysis of the simulation results.

The first example is in calculating the equilibrium concentration of Styrene using HYSYS. It should be noted that this problem is not in the new version of HYSYS 3.0.1.

\section{Equilibrium Constant in a Reaction rate in a PFR Reactors: HYSYS By Robert P. Hesketh $\quad$ Spring 2002}

In this session you will learn how to use equilibrium constants within a reaction rate expression in HYSYS. You will use the following HYSYS reactors

- simple reaction rate expression in a PFR

- equilibrium reaction rate in an Equilibrium Reactor

- Gibbs reactor. .

\section{Table of Contents}

Reactors 
Reaction Sets (portions from Simulation Basis: Chapter 4 Reactions) ............................................ 5

HYSYS PFR Reactors Tutorial using Styrene with Equilibrium Considerations ....................... 5

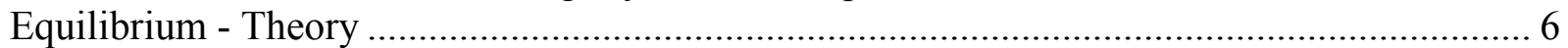

Hand Calculations for Keq..................................................................................... 9

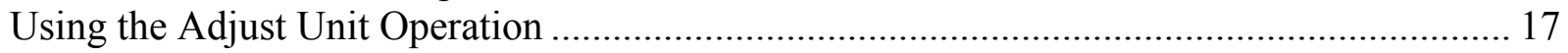

Examine Equilibrium Results at Large Reactor Volumes ............................................ 18

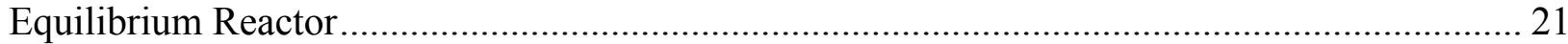

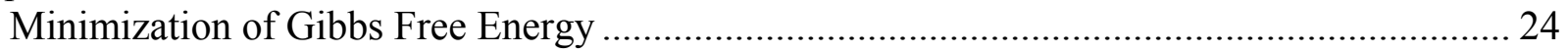

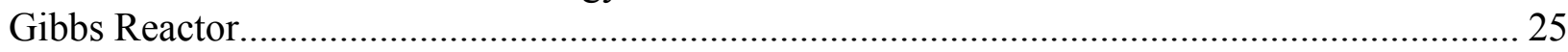

The references for this section are taken from the 2 HYSYS manuals:

Simulation Basis: Chapter 4 Reactions

Steady-State Modeling: Chapter 9 Reactors

Reactors.

Taken from: 9.7 Plug Flow Reactor (PFR) Property View

The PFR (Plug Flow Reactor, or Tubular Reactor) generally consists of a bank of cylindrical pipes or tubes. The flow field is modeled as plug flow, implying that the stream is radially isotropic (without mass or energy gradients). This also implies that axial mixing is negligible.

As the reactants flow the length of the reactor, they are continually consumed, hence, there will be an axial variation in concentration. Since reaction rate is a function of concentration, the reaction rate will also vary axially (except for zero-order reactions).

To obtain the solution for the PFR (axial profiles of compositions, temperature, etc.), the reactor is divided into several subvolumes. Within each subvolume, the reaction rate is considered to be spatially uniform.

You may add a Reaction Set to the PFR on the Reactions tab. Note that only Kinetic, Heterogeneous Catalytic and Simple Rate reactions are allowed in the PFR.

Reaction Sets (portions from Simulation Basis: Chapter 4 Reactions)

Reactions within HYSYS are defined inside the Reaction Manager. The Reaction Manager, which is located on the Reactions tab of the Simulation Basis Manager, provides a location from which you can define an unlimited number of Reactions and attach combinations of these Reactions in Reaction Sets. The Reaction Sets are then attached to Unit Operations in the Flowsheet.

\section{HYSYS PFR Reactors Tutorial using Styrene with Equilibrium Considerations}

Styrene is a monomer used in the production of many plastics. It has the fourth highest production rate behind the monomers of ethylene, vinyl chloride and propylene. Styrene is made from the dehydrogenation of ethylbenzene:

$$
\mathrm{C}_{6} \mathrm{H}_{5}-\mathrm{C}_{2} \mathrm{H}_{5} \Leftrightarrow \mathrm{C}_{6} \mathrm{H}_{5}-\mathrm{CH}=\mathrm{CH}_{2}+\mathrm{H}_{2}
$$


In this reactor we will neglect the aspect that reaction 2 is an equilibrium reaction and model this system using a power law expression. In HYSYS this is called a Kinetic Rate expression. The reaction rate expression that we will use in this tutorial is from Hermann ${ }^{17}$ and has been modified by removing the reverse reaction rate:

$$
r_{E B}=-7.491 \times 10^{-2} \frac{\mathrm{mol} \mathrm{EB}}{\mathrm{g}_{\mathrm{cat}} \mathrm{s} \mathrm{kPa}} \exp \left[-\frac{21874 \mathrm{cal} / \mathrm{mol}}{\left(1.987 \frac{\mathrm{cal}}{\mathrm{mol} \mathrm{K}}\right) T}\right]\left(p_{E B}-\frac{p_{\text {Styrene }} p_{H_{2}}}{K_{P}}\right)
$$

Notice that the reaction rate has units and that the concentration term is partial pressure with units of $\mathrm{kPa}$.

HYSYS Reaction rates are given in units of volume of gas phase. For example, to convert from units of kgcat given in equation 4 to the units required by HYSYS given in equation 5 , you must use equation 6.5

$$
\begin{gathered}
r \quad[=] \frac{\mathrm{mol}}{\mathrm{s} \mathrm{kgcat}} \\
r_{H Y S Y S}[=] \frac{\mathrm{mol}}{\mathrm{s} \mathrm{m}_{\mathrm{gas}}^{3}} \\
r_{H Y S Y S}=r \rho_{c} \frac{(1-\phi)}{\phi}
\end{gathered}
$$

From the source of the original reaction rate studies ${ }^{17}$ the properties of the catalyst and reactor are given as:

$$
\begin{gathered}
\phi=0.445 \\
\rho_{\text {cat }}=2146 \mathrm{~kg}_{\text {cat }} / \mathrm{m}_{\text {cat }}^{3} \\
D_{p}=4.7 \mathrm{~mm}
\end{gathered}
$$

For our rates we have been using the units $\mathrm{mol} /(\mathrm{L} \mathrm{s})$. Take out a piece of paper and write down the conversion from gcat to HYSYS units. Verify with your neighbor that you have the correct reaction rate expression. Please note that if you change the void fraction in your simulation you will need to also change the reaction rate that is based on your void fraction.

\section{Equilibrium - Theory}

In HYSYS, for most reactions you will need to input the equilibrium constant as a function of temperature. The equilibrium constant is defined by equation as

$$
K=\exp \left(\frac{-\Delta G_{r x n}}{R T}\right)
$$

for the stoichiometry given by equation 2 the equilibrium constant is defined in terms of activities as

$$
K=\frac{a_{\text {styrene }} a_{H_{2}}}{a_{E B}}
$$

for a gas the activity of a species is defined in terms of its fugacity

$$
a_{i}=\frac{f_{i}}{f_{i}^{0}}=\frac{f_{i}}{1 \mathrm{~atm}}=\gamma_{i} p_{i}
$$


where $\gamma_{i}$ has units of $\mathrm{atm}^{-1}$.

Now combining equations 10, 11, and 12 results in the following for our stoichiometry given in equation 2,

$$
K_{P}=\exp \left(\frac{-\Delta G_{r x n}}{R T}\right) \mathrm{atm}
$$

It is very important to note that the calculated value of $K_{p}$ will have units and that the units are $1 \mathrm{~atm}$, based on the standard states of gases.

To predict $\Delta G_{r x n}$ as a function of temperature we will use the fully integrated van't Hoff equation given in by Fogler ${ }^{18}$ in Appendix $\mathrm{C}$ as

$$
\ln \frac{\left.K_{P}\right|_{T}}{\left.K_{P}\right|_{T_{R}}}=\frac{\left.\Delta H_{R}^{o}\right|_{T_{R}}-T_{R} \Delta \hat{C}_{p}}{R}\left(\frac{1}{T_{R}}-\frac{1}{T}\right)+\frac{\Delta \hat{C}_{p}}{R} \ln \left(\frac{T}{T_{R}}\right)
$$

Now we can predict $\left.K_{P}\right|_{T}$ as a function of temperature knowing only the heat of reaction at standard conditions (usually $25^{\circ} \mathrm{C}$ and 1 atm and not STP!) and the heat capacity as a function of temperature. What is assumed in this equation is that all species are in one phase, either all gas or all vapor. For this Styrene reactor all of the species will be assumed to be in the gas phase and the following modification of equation 14 will be used

$$
\ln \frac{\left.K_{P}\right|_{T}}{\left.K_{P}\right|_{T_{R}}}=\frac{\left.\Delta H_{R}^{o}\right|^{\text {vapor }} T_{R}-T_{R} \Delta \hat{C}_{p}^{\text {vapor }}}{R}\left(\frac{1}{T_{R}}-\frac{1}{T}\right)+\frac{\Delta \hat{C}_{p}^{\text {vapor }}}{R} \ln \left(\frac{T}{T_{R}}\right)
$$

The heat capacity term is defined as

$$
\hat{C}_{p}^{\text {vapor }}=\frac{\int_{T_{R}}^{T} C_{p}^{\text {vapor }} \mathrm{d} T}{\left(T-T_{R}\right)}
$$

and for the above stoichiometry

$$
\Delta \hat{C}_{p}^{\text {vapor }}=\hat{C}_{p_{\text {syrene }}}^{\text {vapor }}+\hat{C}_{p_{H_{2}}}^{\text {vapor }}-\hat{C}_{p_{E B}}^{\text {vapor }}
$$

Now for some hand calculations!

To determine the equilibrium conversion for this reaction we substitute equation 12 into equation 11 yielding

$$
K_{P}=\frac{p_{\text {styrene }} p_{H_{2}}}{p_{E B}}
$$

Defining the conversion based on ethylbenzene (EB) and defining the partial pressure in terms of a molar flowrate gives:

$$
p_{i}=\frac{F_{i}}{F_{T}} P=\frac{\left(F_{i_{0}}-F_{E B_{0}} \chi_{E B}\right)}{F_{T}} P
$$

Substituting equation 19 for each species into equation 18 with the feed stream consisting of no products and then simplifying gives

$$
K_{P}=\frac{P}{F_{T}}\left(\frac{F_{E B_{0}} \chi_{E B}^{2}}{1-\chi_{E B}}\right)
$$


where the total molar flow is given by

$$
F_{T}=F_{E B}+F_{\text {styrene }}+F_{H_{2}}+F_{\text {steam }}
$$

With the use of a Stoic table the total flowrate can be defined in terms of conversion as

$$
F_{T}=F_{E B_{0}}+F_{\text {steam }_{0}}+F_{E B_{0}} \chi_{E B}
$$

Substituting equation 22 into equation 20 gives the following equation

$$
K_{P}=\frac{P}{\left(F_{T 0}+F_{E B_{0}} \chi_{E B}\right)}\left(\frac{F_{E B_{0}} \chi_{E B}^{2}}{1-\chi_{E B}}\right)
$$

The above equation can be solved using the quadratic equation formula and is

$$
\chi_{E B}=\frac{-K_{P} F_{\text {steam }_{0}}+\sqrt{\left(K_{P} F_{\text {steam }_{0}}\right)^{2}+4 F_{E B_{0}}\left(P+K_{P}\right) K_{P} F_{T 0}}}{2 F_{E B_{0}}\left(P+K_{P}\right)}
$$

There are 2 very important aspects to Styrene reactor operation that can be deduced from equation 23. Knowing that at a given temperature $K_{p}$ is a constant then

1. Increasing $\mathrm{P}$ will decrease $\chi_{\mathrm{EB}}$

2. Increasing the total molar flowrate by adding an inert such as steam will increase $\chi_{\mathrm{EB}}$

The following page gives sample calculations for all of the above. From these sample calculations at a temperature of $880 \mathrm{~K}$ the equilibrium constant is $0.221 \mathrm{~atm}$. At an inlet flowrate of $152.2 \mathrm{~mol}$ ethylbenzene/s and no steam the conversion is 0.372 . At an inlet flowrate of 152.2 mol ethylbenzene/s and a steam flowrate of 10 times the molar flowrate of ethylbenzene the conversion increases to 0.723 .

Once you have calculated $K_{p}$ as a function of temperature, then you can enter this data into a table for the reaction rate. 
Equilibrium Cake.

CASE, No steam

$$
\begin{aligned}
& F_{E B_{0}}=152.2 \mathrm{~mol} / \mathrm{s} \\
& F_{\text {Steam o }}=0 \\
& P_{0}=1.378 \mathrm{~atm} \\
& T=880 \mathrm{~K} \\
& K_{p}=0.221 \mathrm{~atm}
\end{aligned}
$$

for CASE I no steam

$$
\begin{aligned}
& X=\frac{0 \pm \sqrt{0+4\left(152.2 \frac{\mathrm{mo}}{\mathrm{s}}\right)(1.378 \mathrm{~atm}+0.221 \mathrm{~atm})(0.221 \mathrm{~atm})(52.2 \mathrm{~mm}}}{2(152.2 \mathrm{~mol} / \mathrm{s})(1.378 \mathrm{~atm}+0.221 \mathrm{~atm})} \\
& x=0.372 \text { (No Steam) }
\end{aligned}
$$

fo CASE 2 with 5 term $/ A C=10$

$$
\begin{aligned}
& -(0.221 \mathrm{~atm})\left(1522 \frac{\mathrm{mwl}}{\mathrm{s}}\right) \pm\left[\left(0.221 \mathrm{~atm} 1522 \frac{\mathrm{mol}}{\mathrm{s}}\right)^{2}+4\left(152.2 \frac{\mathrm{mol}}{\mathrm{s}}\right)[1.378+0.221](0.221) / 674,2\right]^{2}
\end{aligned}
$$

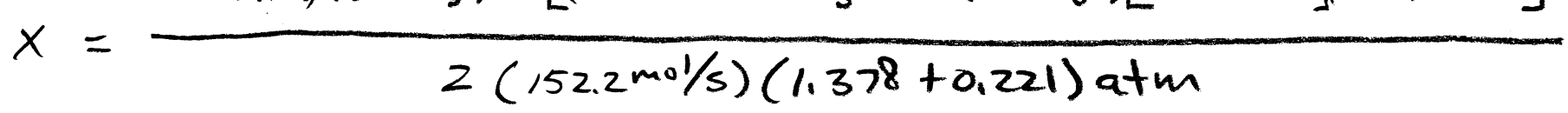

$$
\begin{aligned}
& x=0.723
\end{aligned}
$$

$\therefore$ presence of Steam increases conversion

$$
K_{P}=\frac{F_{S} F_{H_{2}}}{F_{\varepsilon B}} \frac{P}{F_{T}}
$$

(1) if $k_{p}=$ constant, then increasing $F_{T}$ will result in an increase in $F_{5} \notin F_{H_{2}}$ and $X$ increases

(2) increase $P$ will cause $X$ to decrease

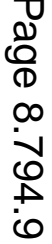


Equilibrium Calculations

Stoic Table

$$
\begin{aligned}
& \Sigma B \quad F_{E B_{0}}-F_{E B_{0}} X \quad F_{E B}=F_{E B_{0}}(1-x) \\
& S \quad 0 \quad+F_{\varepsilon B_{0}} X \quad F_{S}=F_{H}=F_{4 B_{0}} X \\
& H \quad 0 \quad+F_{E B_{\Delta}} X \quad F_{H}=F_{\varepsilon B_{0}} x \\
& P_{i}=\frac{F_{i}}{F_{T}} P \\
& F_{T}=F_{E B_{0}}+F_{w_{0}}+F_{\varepsilon B_{0}} X \\
& k_{p}=\frac{F_{E B_{0}} x_{E B}^{2} P}{F_{T}\left(1-x_{\varepsilon B}\right)}=\frac{F_{\varepsilon B_{0}} x^{2} P}{\left(F_{T_{0}}+F_{\varepsilon B_{0}} x\right)(1-x)}
\end{aligned}
$$

$$
\begin{aligned}
& \left(k \rho F_{T_{0}}+k_{\rho} F_{\varepsilon B_{0}} x\right)(1-x)=F_{\varepsilon B_{0}} x^{2} p \\
& k_{\rho} F_{T_{0}}+k_{\rho} F_{\varepsilon B_{0}} x-k_{\rho} F_{T_{0}} x-k_{p} F_{\varepsilon B_{0}} x^{2}=F_{\varepsilon B_{0}} x^{2} p \\
& k_{p} F_{w} \\
& x^{2}\left(F_{\varepsilon B_{0}}+k_{P} F_{\varepsilon B_{0}}\right)+x\left(k_{P} F_{T_{0}}-k_{P} F_{\varepsilon B_{0}}\right)-k_{P} F_{T_{0}}=0 \\
& \frac{-b \pm \sqrt{b^{2}-4 a c}}{2 a} \text { where } a x^{2}+b x+c=0 \\
& x=\frac{-k_{p}\left(F w_{0}\right) \pm \sqrt{\left(k_{p} F_{w_{0}}\right)^{2}+4 F_{\varepsilon B_{0}}\left(P+k_{p}\right) k_{p} F_{T_{0}}}}{2 F_{2 B_{0}}\left(P+k_{p}\right)}
\end{aligned}
$$

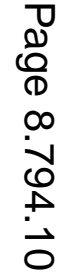


Procedure to Install a Reaction Rate with an Equilibrium Constant - Simple Reaction Rates

1. Start HYSYS

2. Since these compounds are hydrocarbons, use the PengRobinson thermodynamic package. (Additional information on HYSYS thermodynamics packages can be found in the Simulation Basis Manual Appendix A:

Property Methods and Calculations. Note an alternative package for this system is the PRSV)

3. Install the chemicals for a styrene reactor: ethylbenzene, styrene, hydrogen and water. If they are not on this list then use the Sort List... button feature.

4. Now return to the Simulation Basis Manager by either closing the Fluid Package Basis-1 window or clicking on the Rxns tab and pressing the Simulation Basis Mgr... button.

5. On the Reactions tab of the Simulation Basis Manager, press the Add Comps button.

6. The Reaction Component Selection view will appear. In the Add Comps group, ensure that the FPkg Pool radio button is selected. This will make only the Fluid Package components available to the Reaction Manager.

7. Highlight the Fluid Package in the Available Fluid Pkgs group.

8. Press the Add This Group of Components button to transfer the fluid package components into the Selected Reaction Components group.

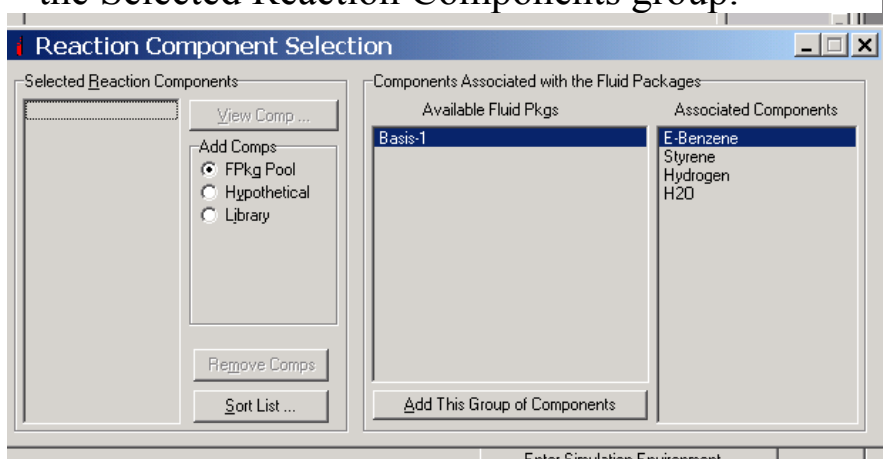

Enter Simulation Environment...
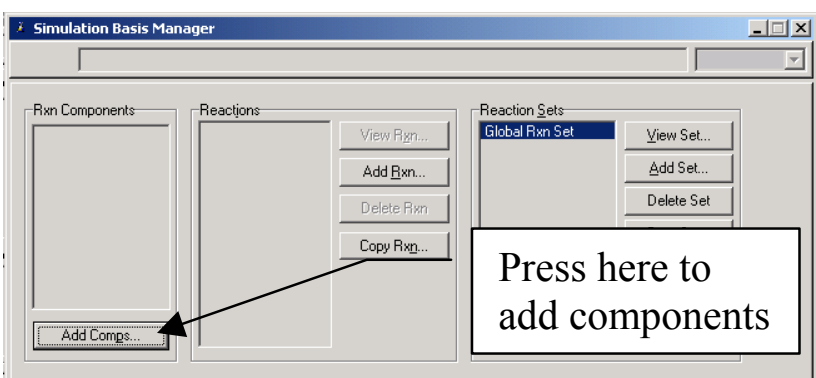

Fluid Pkgs Hypotheticals Oil Manager Reactions Component Maps UserProperty

Enter Simulation Environment...

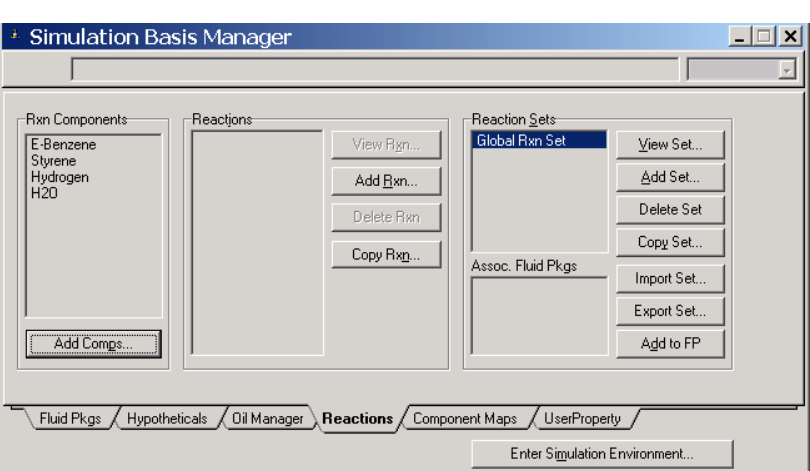

9. Press the Close button $\square$ to return to the

Reactions tab. The selected components are present in the Rxn Components group.

10. To install a reaction, press the Add Rxn button. 
11. From the Reactions view, highlight the Simple Rate reaction type and press the Add Reaction button. Refer to Section 4.4 of the Simulation Basis Manual for information concerning reaction types and the addition of reactions.

12. On the Stoichiometry tab select the first row of the Component column in Stoichiometry Info matrix. Select ethylbenzene from the drop down list in the Edit Bar. The Mole Weight column should automatically provide the molar weight of ethylbenzene. In the Stoich Coeff field enter -1 (i.e. 1 moles of ethylbenzene will be consumed).

13. Now define the rest of the Stoichiometry tab as shown in the adjacent figure.
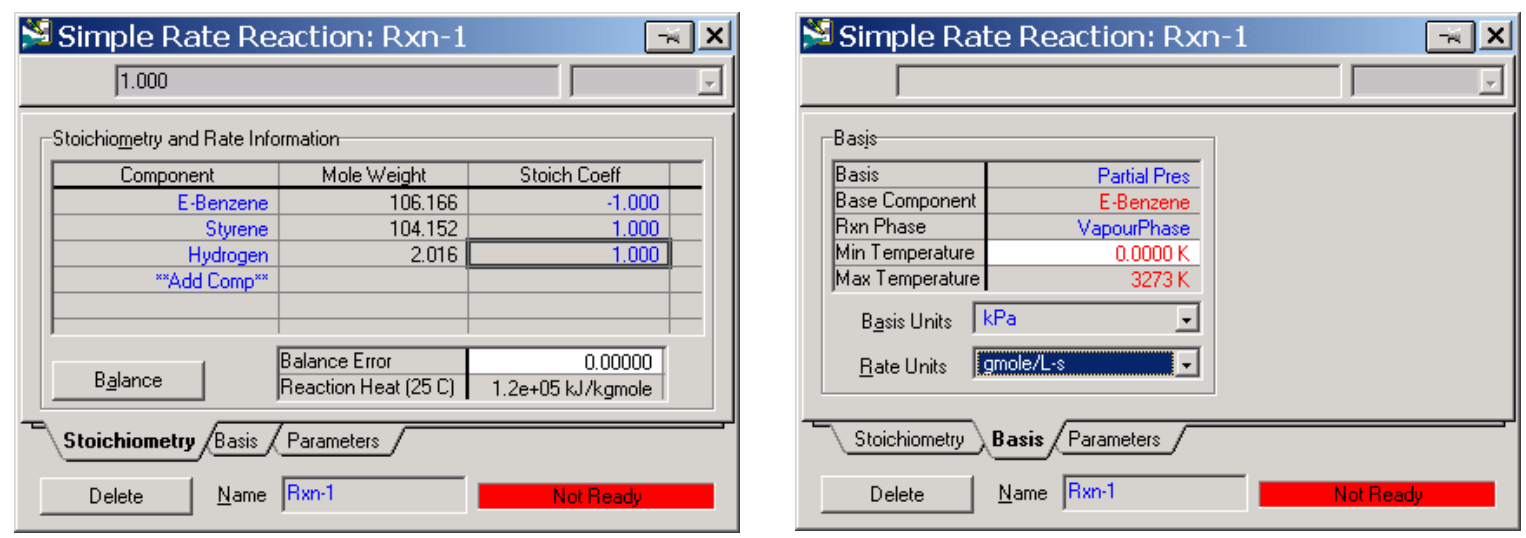

14. Go to Basis tab and set the Basis as partial pressure, the base component as ethylbenzene and have the reaction take place only in the vapor phase.

15. The pressure basis units should be $\mathrm{kPa}$ and the units of the reaction rate given by equation 25 is $\mathrm{mol} /(\mathrm{L} \mathrm{s})$. Since the status bar at the bottom of the property view shows Not Ready, then go to the Parameters tab.

16. Next go to the Parameters tab and enter the activation energy from equation 3 is $E_{a}=21874 \mathrm{cal} / \mathrm{mol}$. Convert the pre-exponential to have units of atm. You must use these rates since HYSYS will only accept Kp values in the standard units of atm.:

$$
\begin{aligned}
A & =7.491 \times 10^{-2}\left(\frac{\mathrm{mol}}{\text { gcat s kPa }}\right) \frac{10^{3} \mathrm{~g}_{\text {cat }}}{\mathrm{kg}_{\text {cat }}}\left(\frac{2146 \mathrm{~kg}_{\text {cat }}}{\mathrm{m}_{\text {cat }}^{3}}\right) \frac{(1-0.445) \mathrm{m}_{\text {cat }}^{3}}{\mathrm{~m}_{\mathrm{R}}^{3}}\left(\frac{\mathrm{m}_{\mathrm{R}}^{3}}{0.445 \mathrm{~m}_{\text {gas }}^{3}}\right) \frac{1 \mathrm{~m}_{\text {gas }}^{3}}{10^{3} \mathrm{~L}_{\text {gas }}} \\
& =200.5 \frac{\mathrm{mol}}{\mathrm{L}_{\text {gas }} \mathrm{s} \mathrm{kPa}}\left(\frac{1 \mathrm{kPa}}{1000 \mathrm{~Pa}}\right) \frac{1.01325 \times 10^{5} \mathrm{~Pa}}{\mathrm{~atm}} \\
& =20315 \frac{\mathrm{mol}}{\text { gcat s atm }}
\end{aligned}
$$

17. Leave $\beta$ blank or place a zero in the cell. Notice that you don't enter the negative sign with the pre-exponential.

18. Now you must regress your equilibrium constant values, with units of atm, using the equation

$$
\ln (K)=A+B / T+C \ln (T)+D T
$$


19. Below is the data table that was shown in the hand calculations. These data can either be regressed using Microsoft Excel's multiple linear Regression or a nonlinear regression program such as polymath. Make sure that the units of $\mathrm{Kp}$ are the same as your basis units.

\begin{tabular}{rr}
$\mathrm{T}(\mathrm{K})$ & \multicolumn{2}{c}{$\mathrm{Kp}(\mathrm{atm})$} \\
$\mathbf{5 0 0}$ & $7.92 \mathrm{E}-07$ \\
$\mathbf{5 5 0}$ & $1.10 \mathrm{E}-05$ \\
$\mathbf{6 0 0}$ & $9.99 \mathrm{E}-05$ \\
$\mathbf{6 5 0}$ & $6.46 \mathrm{E}-04$ \\
$\mathbf{7 0 0}$ & $3.20 \mathrm{E}-03$ \\
$\mathbf{7 5 0}$ & 0.013 \\
$\mathbf{7 7 5}$ & 0.024 \\
$\mathbf{8 0 0}$ & 0.043 \\
$\mathbf{8 1 0}$ & 0.054 \\
$\mathbf{8 2 0}$ & 0.067 \\
$\mathbf{8 3 0}$ & 0.082 \\
$\mathbf{8 4 0}$ & 0.101 \\
$\mathbf{8 5 0}$ & 0.124 \\
$\mathbf{8 6 0}$ & 0.151 \\
$\mathbf{8 7 0}$ & 0.183 \\
$\mathbf{8 8 0}$ & 0.221 \\
$\mathbf{8 9 0}$ & 0.266 \\
$\mathbf{9 0 0}$ & 0.318 \\
$\mathbf{9 1 0}$ & 0.379 \\
$\mathbf{9 2 0}$ & 0.450 \\
$\mathbf{9 3 0}$ & 0.532 \\
$\mathbf{9 5 0}$ & 0.736 \\
$\mathbf{9 7 0}$ & 1.003 \\
$\mathbf{9 9 0}$ & 1.348 \\
$\mathbf{1 0 1 0}$ & 1.791 \\
$\mathbf{1 0 3 0}$ & 2.351 \\
$\mathbf{1 0 5 0}$ & 3.051
\end{tabular}

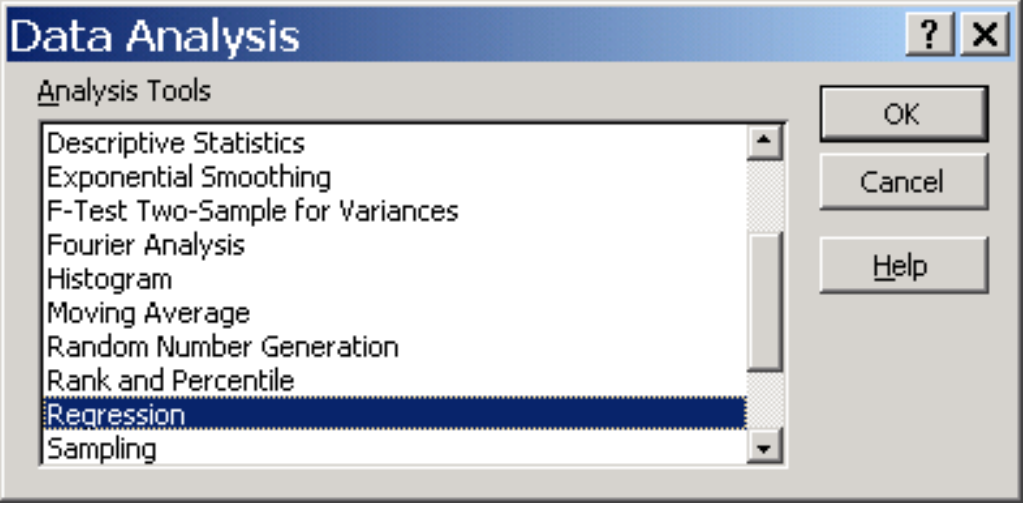

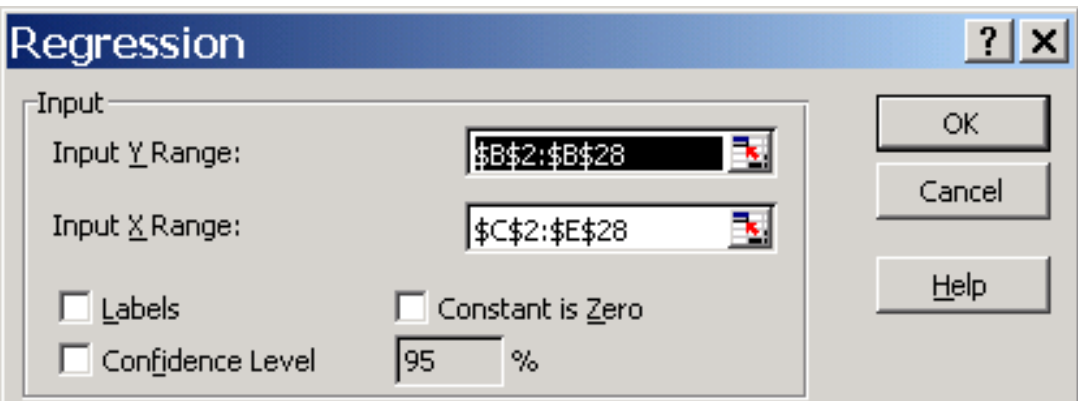

Output options

c output Range:

C New Worksheet Ply:

C New workbook

Residuals

$\sqrt{\nabla}$ Residuals $\quad \square$ Residual Plots

$\nabla$ Standardized Residuals $\quad \nabla$ Line Fit Plots

Normal Probability

ГNormal Probability Plots

\begin{tabular}{ll}
\hline & Coefficients \\
\hline A & -13.2117277 \\
B & -13122.4699 \\
C & 4.353627619 \\
D & -0.00329709 \\
\hline
\end{tabular}

20. Close the Simple Rate Window 
21. By default, the Global Rxn Set is present within the Reaction Sets group when you first display the Reaction Manager. However, for this procedure, a new Reaction Set will be created. Press the Add Set button. HYSYS provides the name Set-1 and opens the Reaction Set property view.

22. To attach the newly created Reaction to

the Reaction Set, place the cursor in the $<$ empty> cell under Active List.

23. Open the drop down list in the Edit Bar and select the name of the Reaction. The Set Type will correspond to the type of Reaction that you have added to the Reaction Set. The status message will now display Ready. (Refer to Section 4.5 - Reaction Sets for details concerning Reactions Sets.)

24. Press the Close button to return to the Reaction Manager.

25. To attach the reaction set to the Fluid Package (your Peng Robinson thermodynamics), highlight Set-1 in the Reaction Sets group and press the Add to FP button. When a Reaction Set is attached to a Fluid Package, it

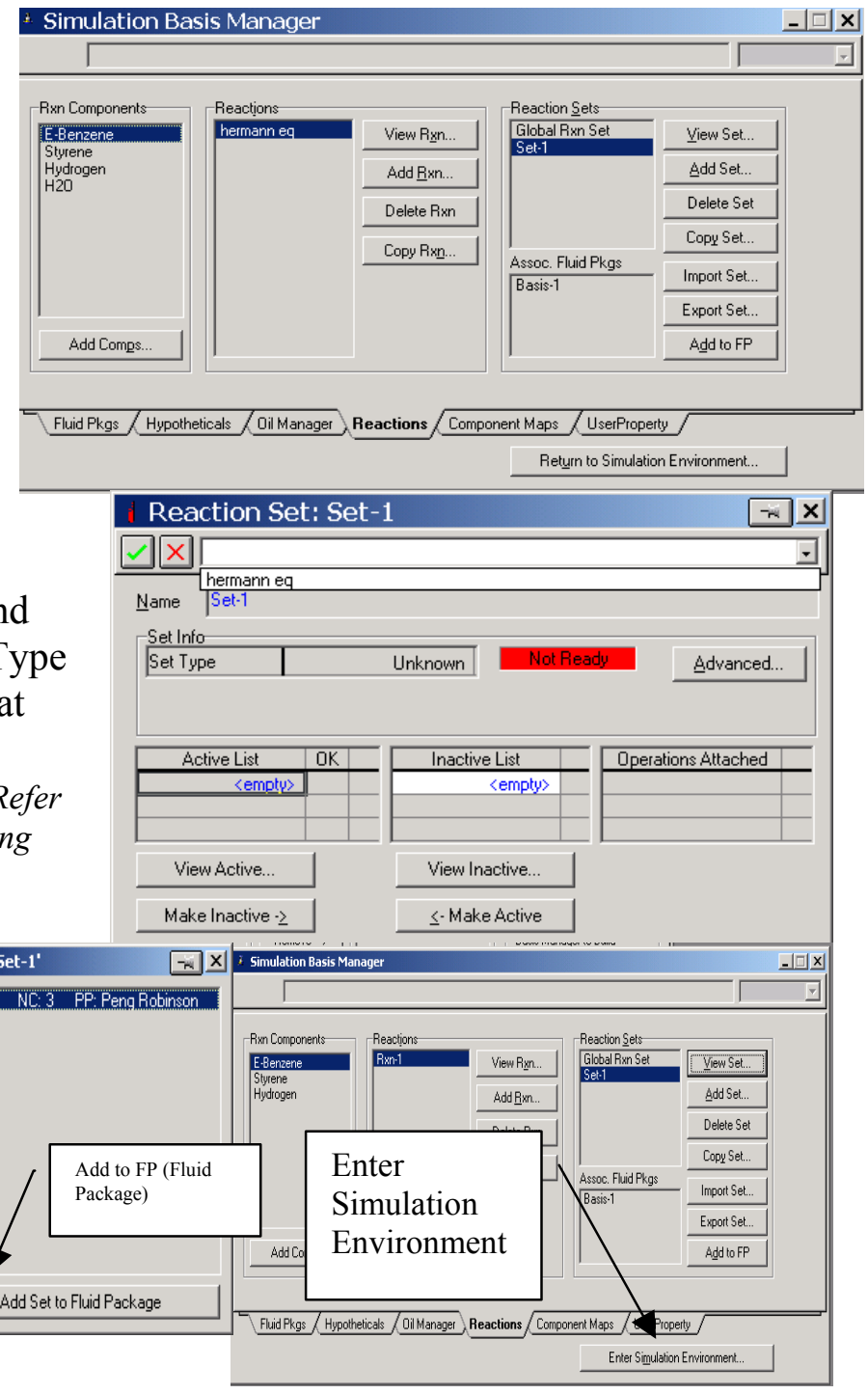
becomes available to unit operations within the Flowsheet using that particular Fluid Package.

26. The Add 'Set-1' view appears, from which you highlight a Fluid Package and press the Add Set to Fluid Package button.

27. Press the Close button. Notice that the name of the Fluid Package (Basis-1) appears in the Assoc. Fluid Pkgs group when the Reaction Set is highlighted in the Reaction Sets group.

28. Now Enter the Simulation Environment by pressing the button in the lower right hand portion

29. Install a PFR reactor. Either through the 29.1. Flowsheet, Add operation 29.2. $\mathrm{f12}$

29.3. or icon pad. Click on PFR, then release left mouse button. Move cursor to pfd screen and press

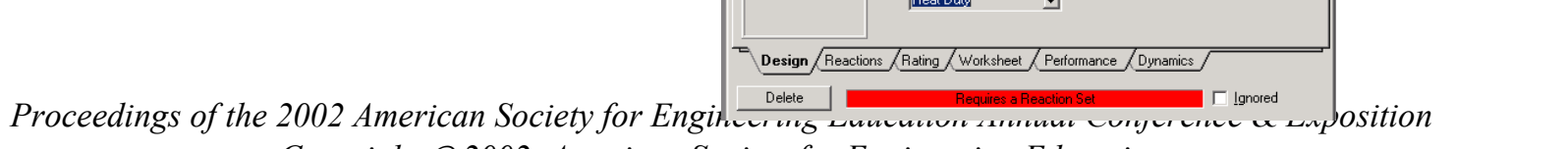
Copyright (C) 2002, American Society for Engineering Education 
left mouse button. Double click on the reactor to open.

30. Add stream names as shown.

31. Next go to the Parameters portion of the Design window. Click on the radio button next to the pressure drop calculation by the Ergun equation.

32. Next add the reaction set by selecting the reactions tab and choosing Reaction Set from the drop down menu.

33. Go to the Ratings Tab. Remember in the case of distillation columns, in which you had to specify the number of stages? Similarly with PFR's you have $t$ specify the volume. In this case add the volume as $250 \mathrm{~m}^{3}, 7 \mathrm{~m}$ length, and a void fraction of 0.445 as shown in the figure.

34. Return to the Reactions tab and modify the specifications for your catalyst.

35. Go to the Design Tab and select heat transfer. To make this reactor adiabatic you need to set the heat duty to zero. For this tutorial we will have an isothermal reactor so leave this unspecified.

36. Close the PFR Reactor

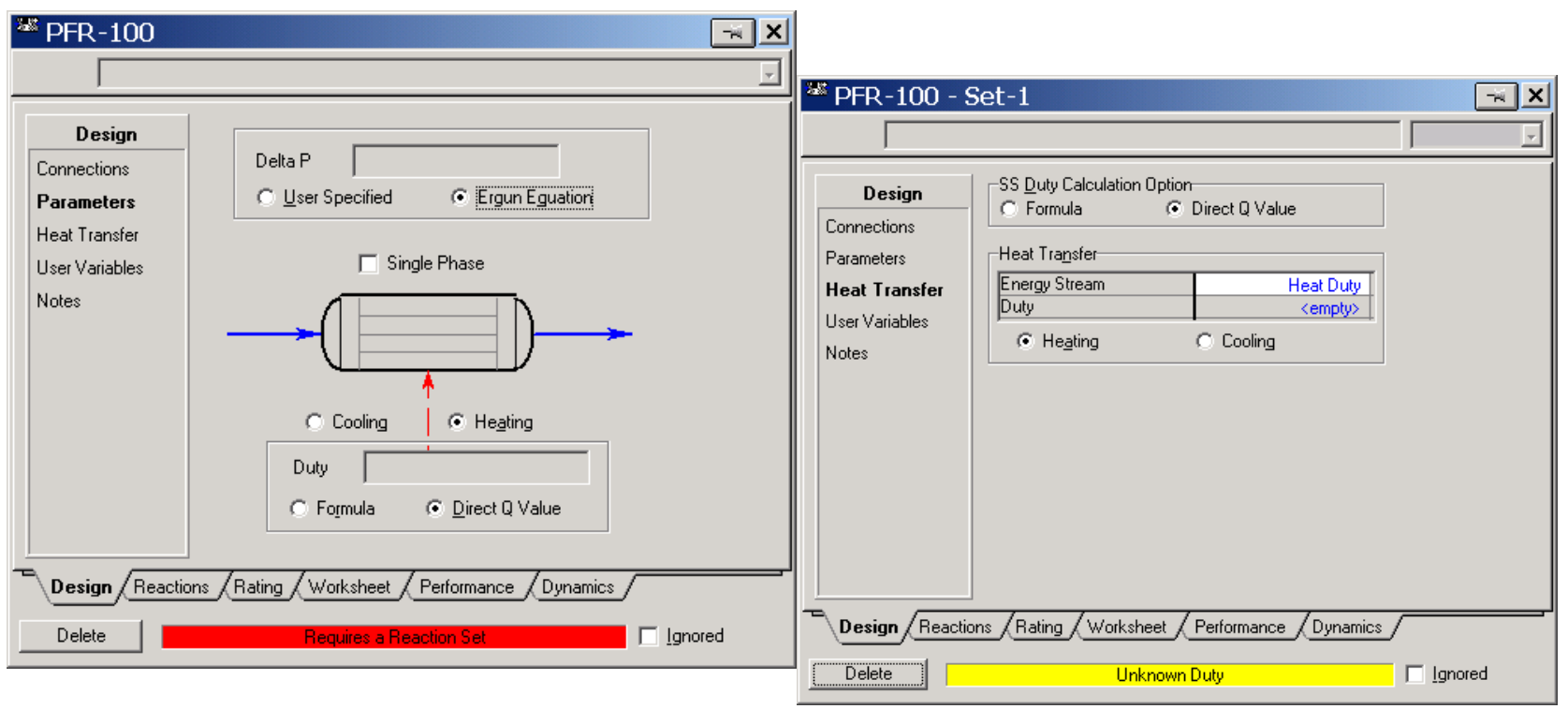

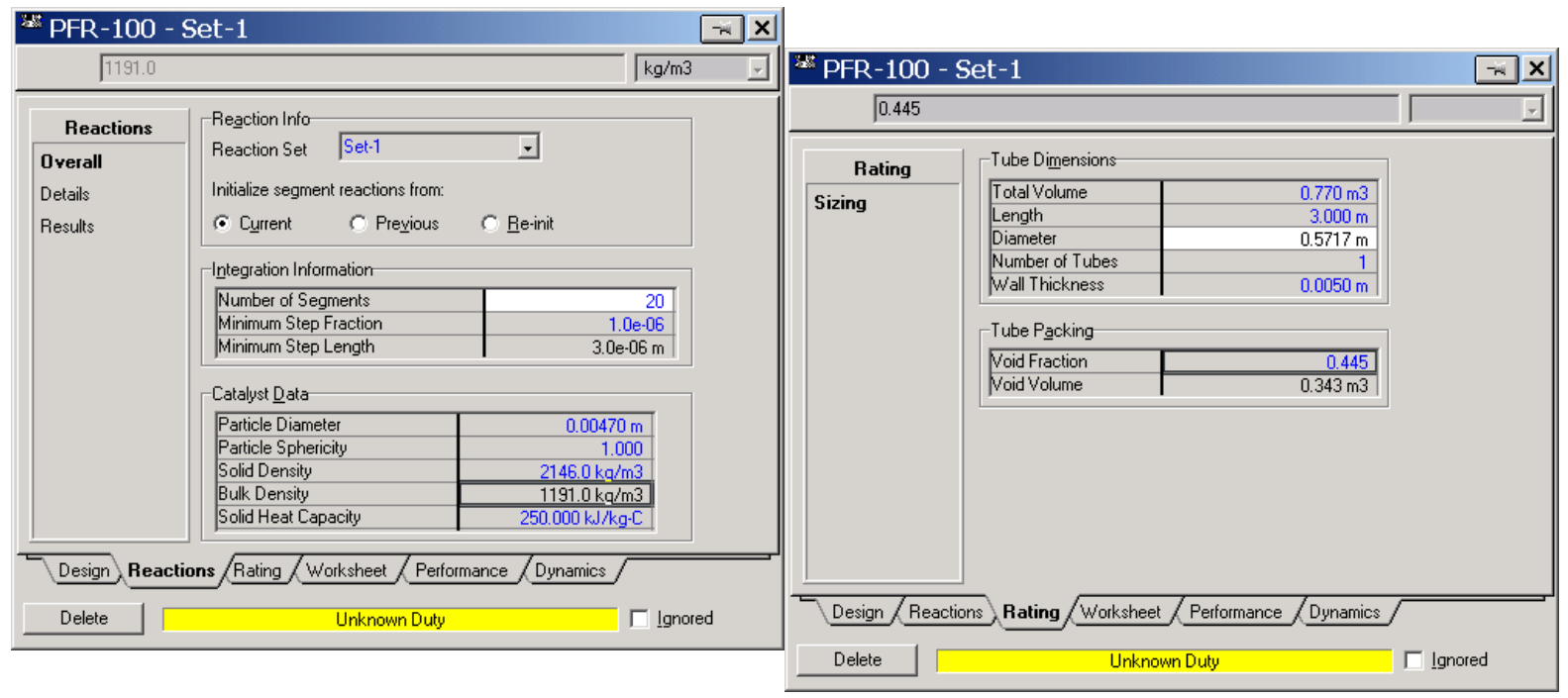

Proceedings of the 2002 American Society for Engineering Education Annual Conference \& Exposition Copyright (C) 2002, American Society for Engineering Education 
37. Open the workbook

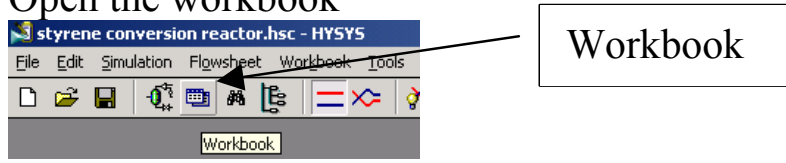

38. Isn't it strange that you can't see the molar flowrate in the composition window? Let's add the molar flowrates to the workbook windows. Go to Workbook setup.

39. Press the Add button on the right side

40. Select Component Molar Flow and then press the All radio button.

41. To change the units of the variables go to Tools, preferences

42. Then either bring in a previously named preference set or go to the variables tab and clone the SI set and give this new set a name.

43. Change the component molar flowrate units from $\mathrm{kmol} / \mathrm{hr}$ to $\mathrm{gmol} / \mathrm{s}$.

44. Change the Flow units from $\mathrm{kmol} / \mathrm{hr}$ to $\mathrm{gmol} / \mathrm{s}$

45. Next change the Energy from $\mathrm{kJ} / \mathrm{hr}$ to $\mathrm{kJ} / \mathrm{s}$.

46. Save preference set as well as the case. Remember that you need to open this preference set every time you use this

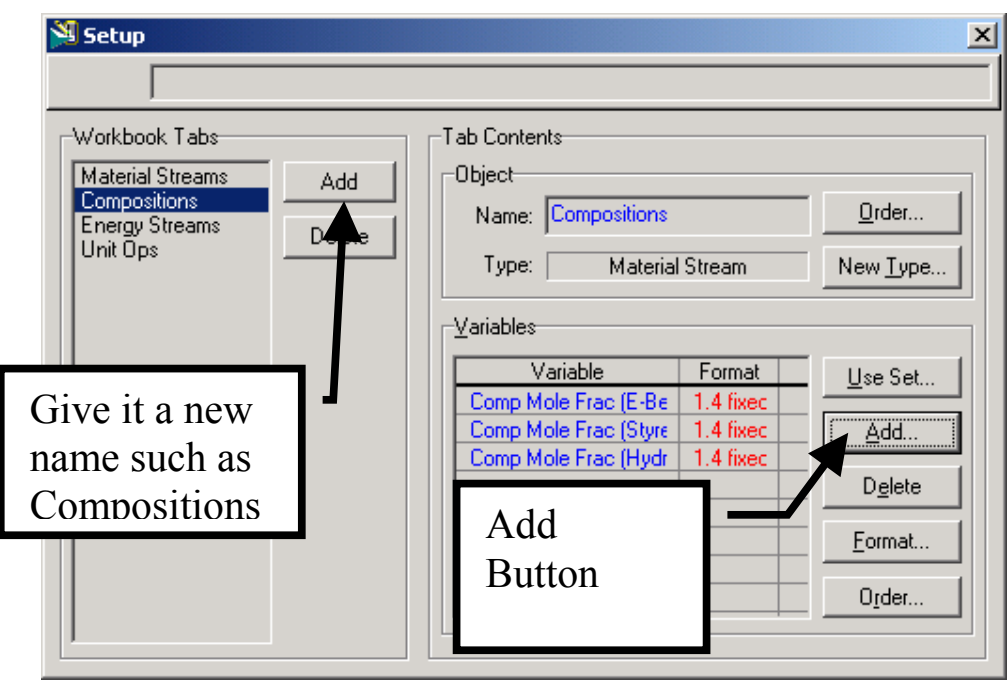
case.

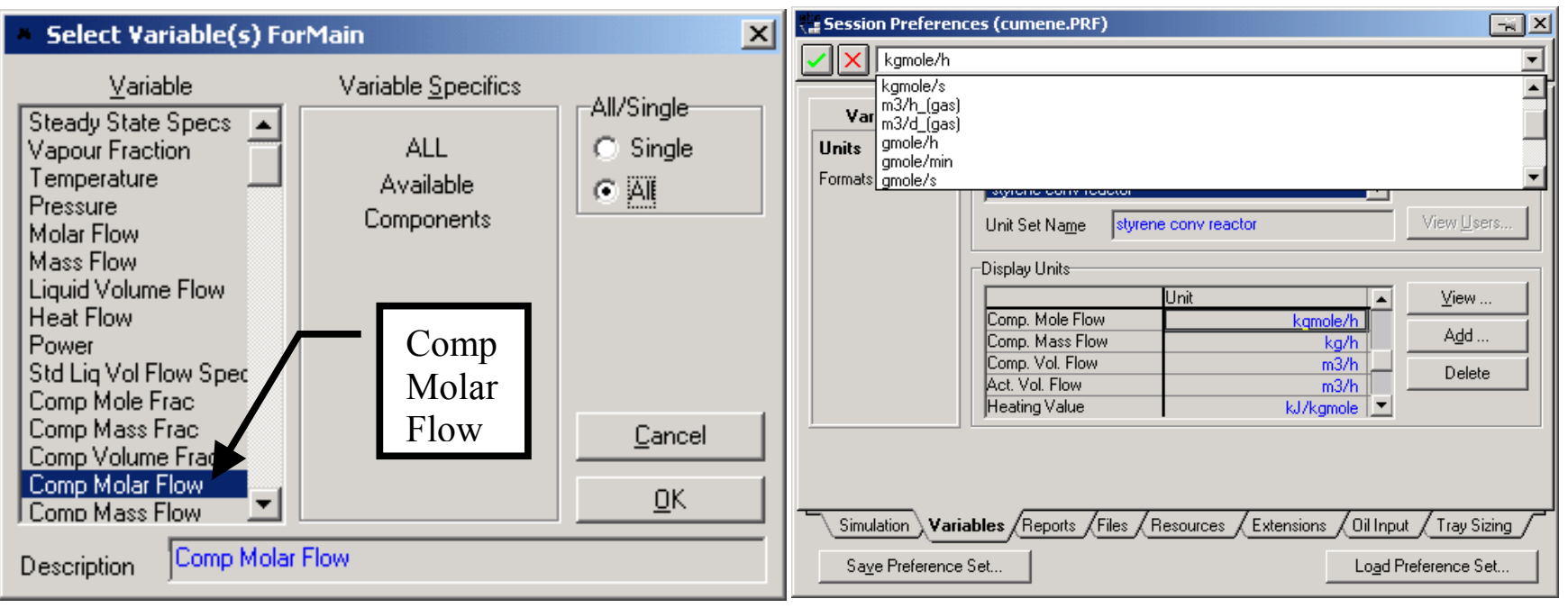




\section{Back to the Simulation}

47. Now add a feed composition of pure ethylbenzene at $152.2 \mathrm{gmol} / \mathrm{s}, 1522 \mathrm{gmol} / \mathrm{s}$ of water, $880 \mathrm{~K}$, and 1.378 bar. Then set the outlet temperature to $880 \mathrm{~K}$ to obtain an isothermal reactor. Remember you can type the variable and then press the space bar and type or select the units.

48. If you get the above message then your reactor has not converged and you need to make adjustments to get your reactor to converge (e.g. the product stream is empty!) Now it is

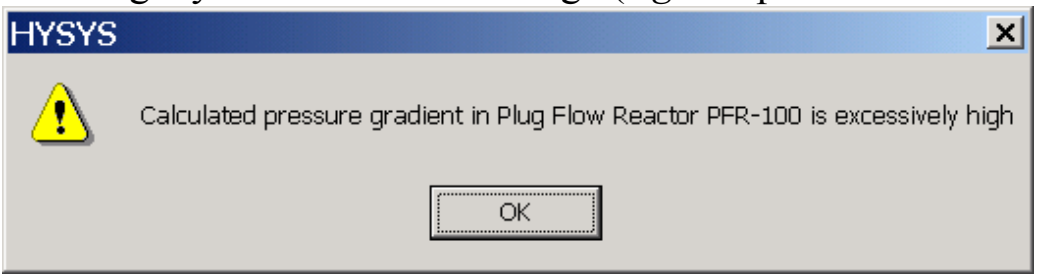

your task to reduce the pressure drop to an acceptable level. What do you need to alter? Refer to the Ergun Equation given by

$$
\frac{\mathrm{d} P}{\mathrm{dz}}=-\frac{G}{\rho D_{p}}\left(\frac{1-\phi}{\phi^{3}}\right)\left[\frac{150(1-\phi) \mu}{D_{p}}+1.75 G\right]
$$

\section{Using the Adjust Unit Operation}

49. Obtain a solution that will meet the following pressure drop specification $\Delta P \leq 0.1 P_{0}$ One way of doing this quickly is to use the adjust function. Go to Flowsheet, Add operation (or press $\mathrm{f} 12$ or the green $\mathrm{A}$ in a diamond on the object palette.

50. Now select the adjusted variable as the tube length and the target variable as the Pressure Drop. Set the pressure drop to $13.78 \mathrm{kPa}$

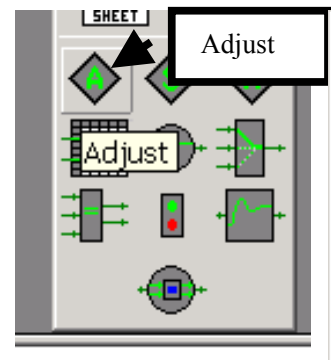
(exactly $10 \%$ of $\mathrm{P} 0$ ).

51. Next go to the Parameters tab and set the

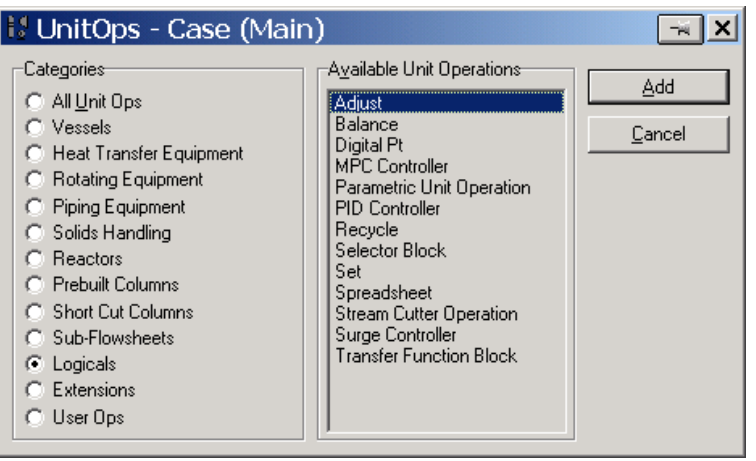
tolerance, step size and maximum iterations.
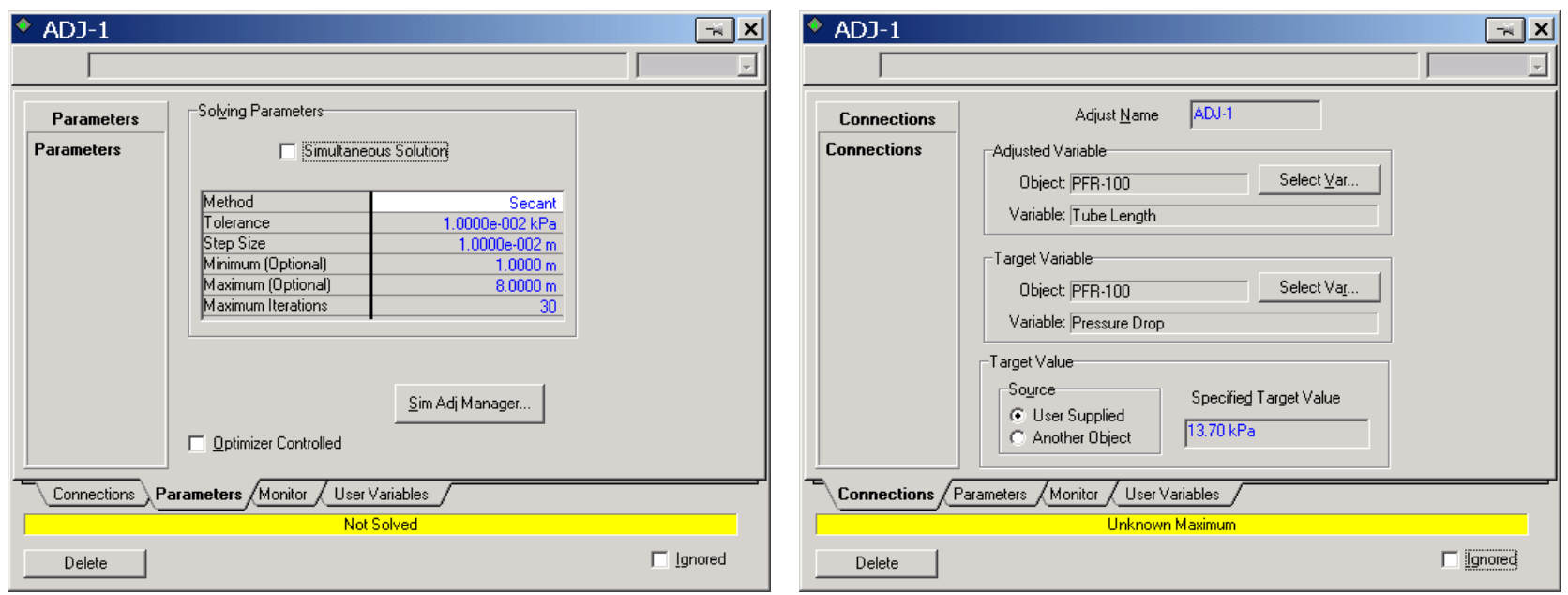

Proceedings of the 2002 American Society for Engineering Education Annual Conference \& Exposition Copyright C 2002, American Society for Engineering Education 
52. If it stops, it may ask you if you want to continue. Answer yes. You can watch the stepping progress by going to the monitor

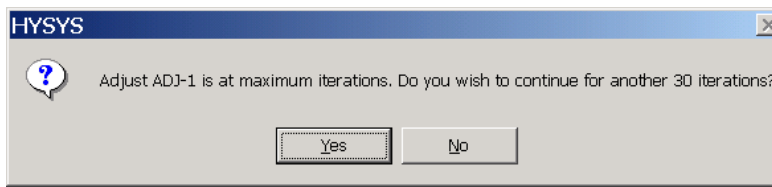
tab.

53. Try this again, but this time get your pressure drop to $1 \%$ of $\mathrm{PO}$.

54. Now turn this Adjust unit off by clicking on the ignore button.

Examine Equilibrium Results at Large Reactor Volumes

55. You equilibrium conversion should be around $72.9 \%$. Comparing this to the previous results for a steam to hydrocarbon molar ratio of 10 gives $72.3 \%$ at 880 and $137.8 \mathrm{kPa}$.

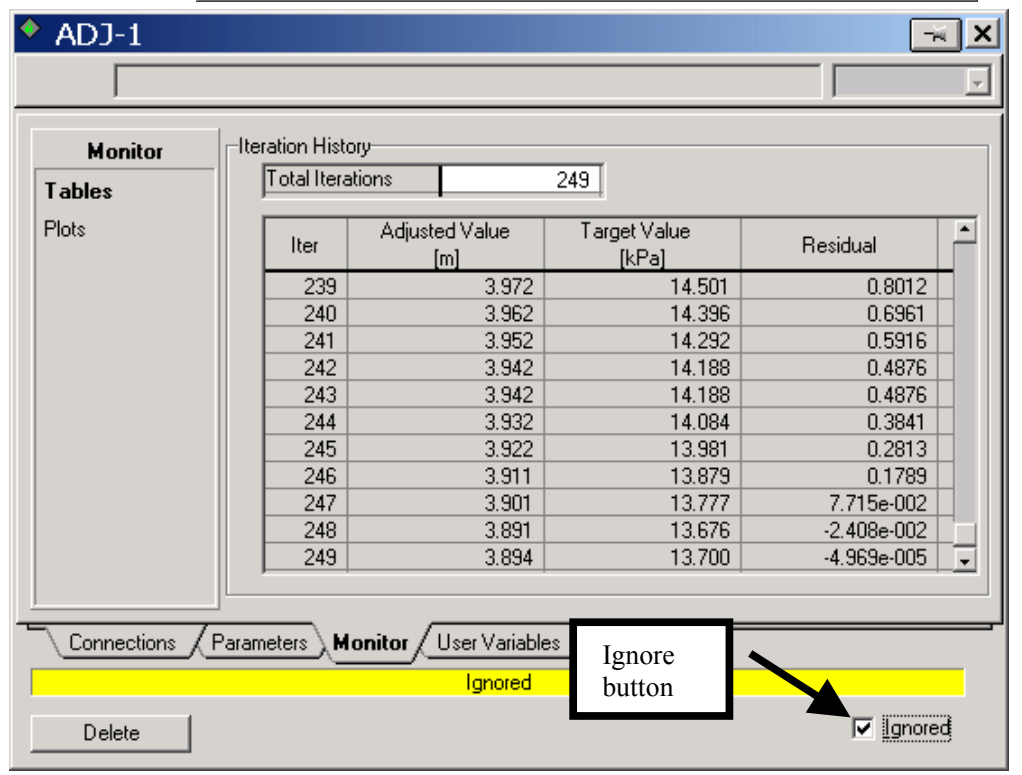

56. Set your pressure drop to zero by turning off the Ergun equation in the Reactor, Design Tab, Parameters option. Set the pressure drop to zero. The conversion is now $72.5 \%$ ! Which is what you calculated by hand.

57. Now set the feed flowrate of steam to zero. You should get a conversion of $37.4 \%$. This again is what your spreadsheet calculation shows for $880 \mathrm{~K}$ and $137.8 \mathrm{kPa}$.

58. Make a plot of Conversion as a function of both reactor temperature and pressure. Becareful how you set up this databook. I had 943 data states by varying both $100 \mathrm{kPa} \leq P \leq 500 \mathrm{kPa}$ and

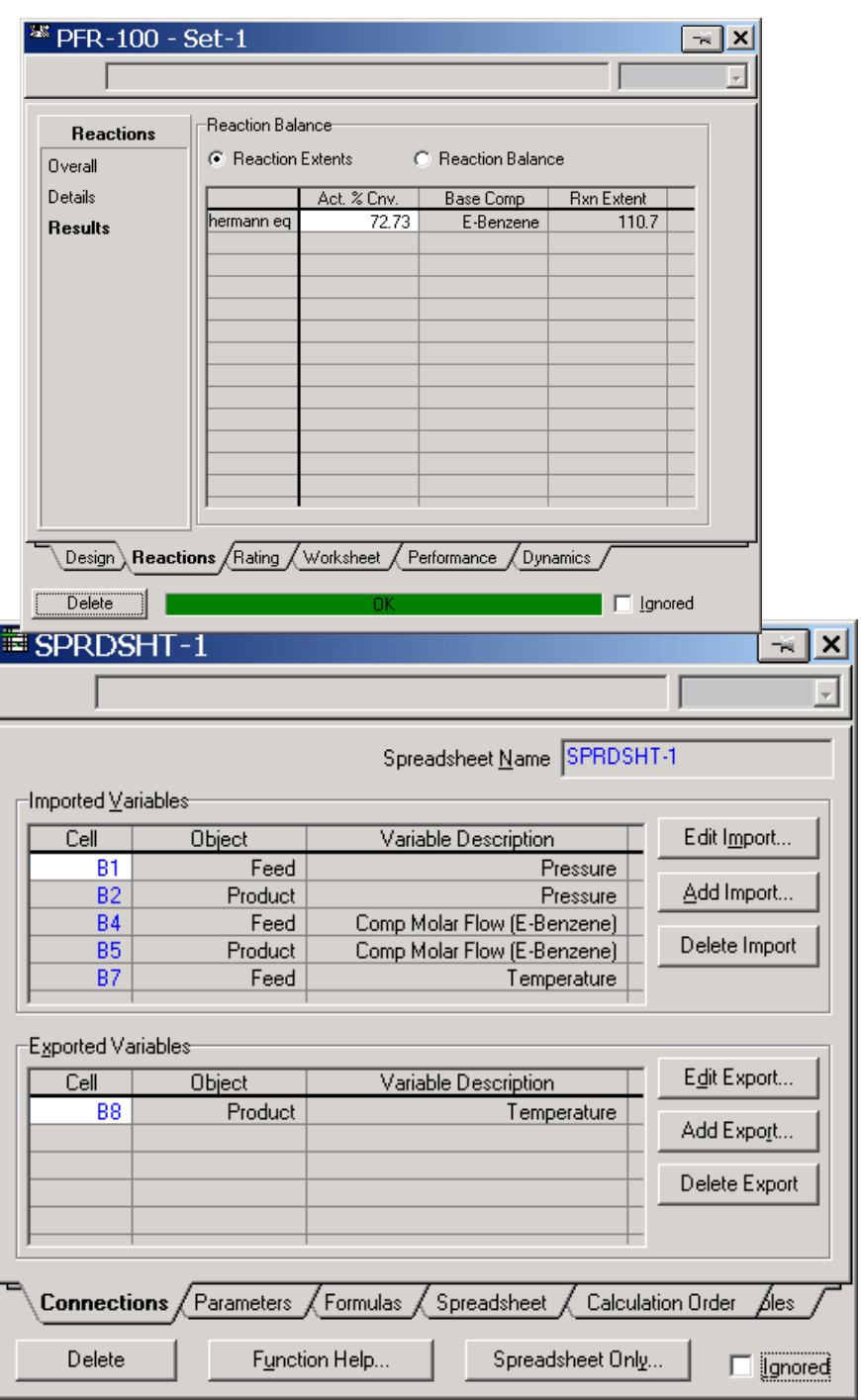


$500 K \leq T \leq 1050 K$. Remember that you have to setup a workbook so that you only need to specify the temperature in one cell.
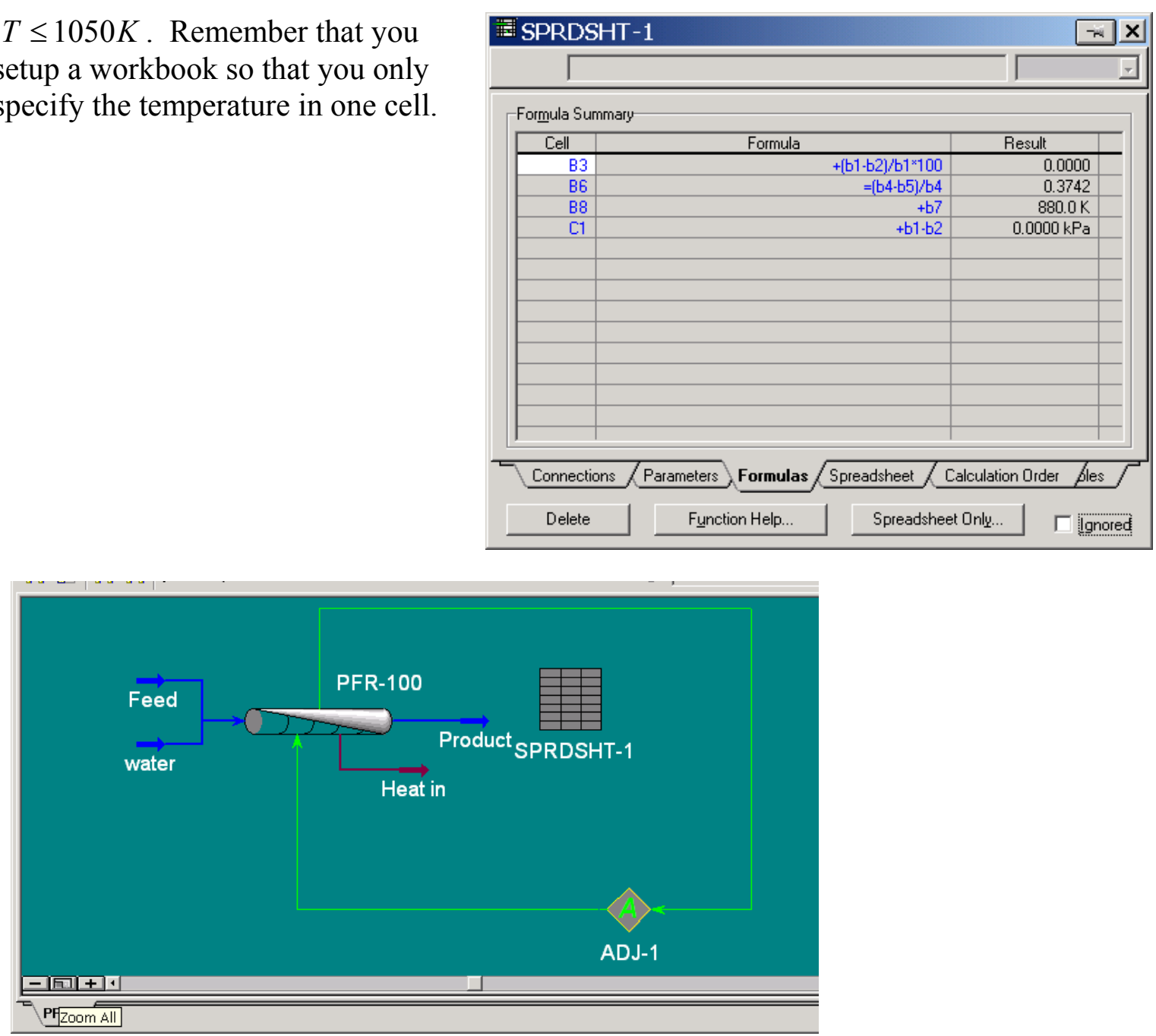

59. Now make a plot of the effect of steam flow on conversion. You will need to add a new feed stream to the reactor.

59.1. Make your Feed stream have only $152.2 \mathrm{~mol}$ of ethylbenzene per second.

59.2. Make a second feed steam called water have a flow of $0 \mathrm{~mol} / \mathrm{s}$. Create a second cell in your spreadsheet that you can export the temperature to both the outlet stream, Product, to make the reactor isothermal and to the Water feed stream temperature.

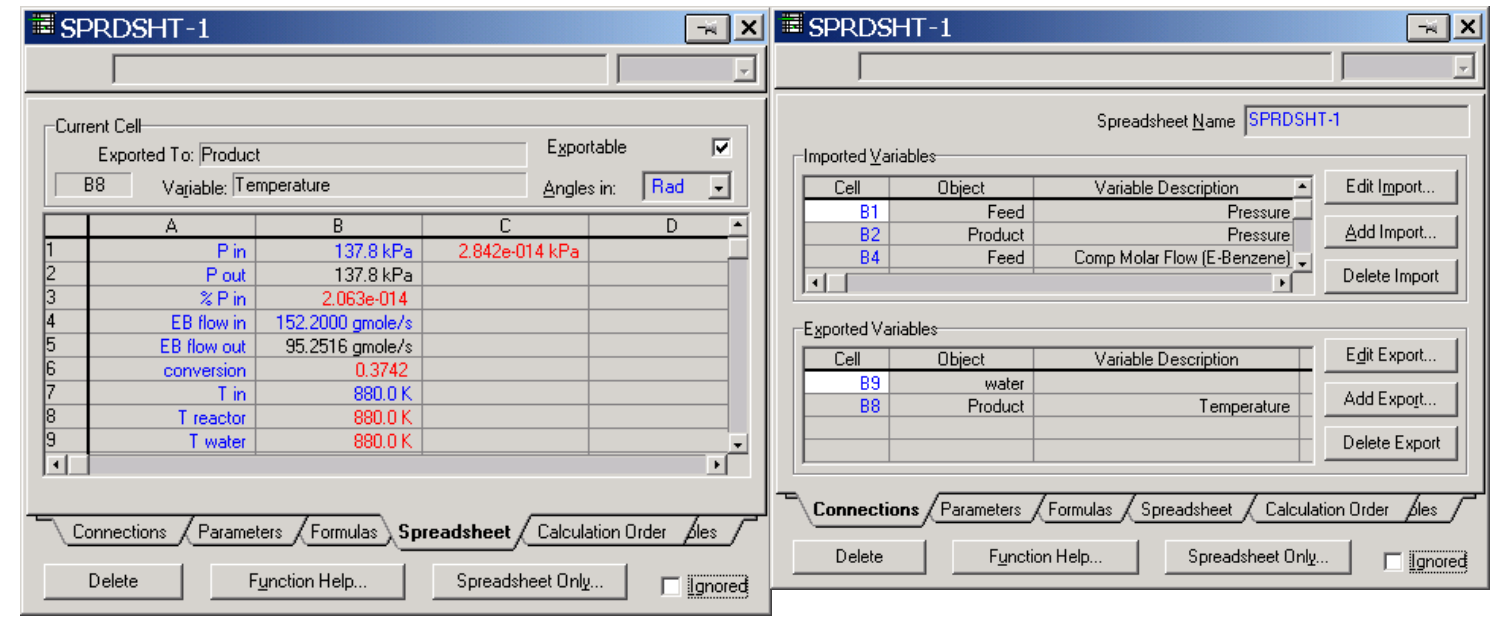

Proceedings of the 2002 American Society for Engineering Education Annual Conference \& Exposition Copyright C 2002, American Society for Engineering Education 

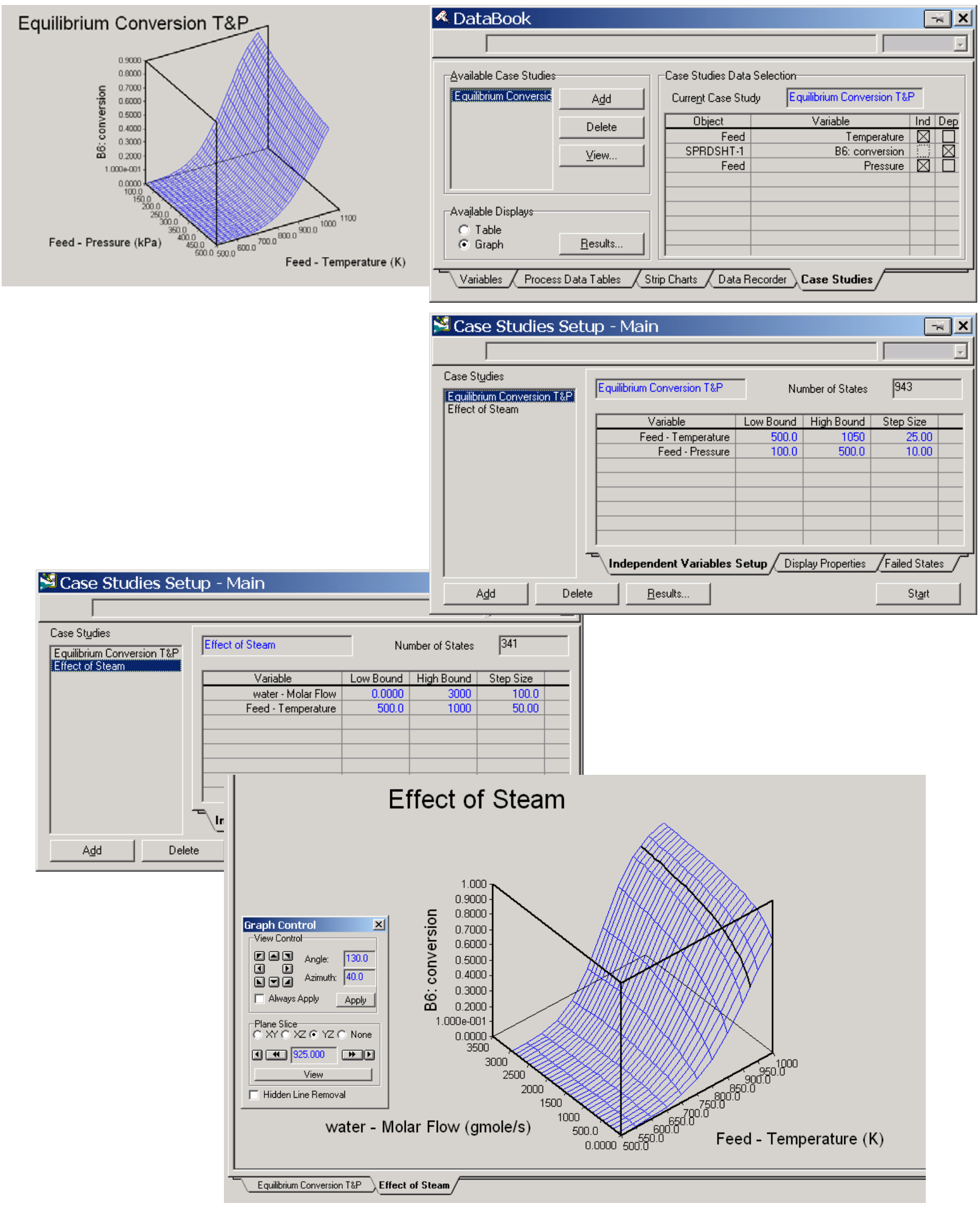

Proceedings of the 2002 American Society for Engineering Education Annual Conference \& Exposition Copyright @ 2002, American Society for Engineering Education 
Equilibrium

Reactor

60. Now we will

install a

second reactor

that only

contains an

equilibrium

reaction. Use

either the

object palette

or the Flowsheet, Add Operation, Equilibrium Reactor.

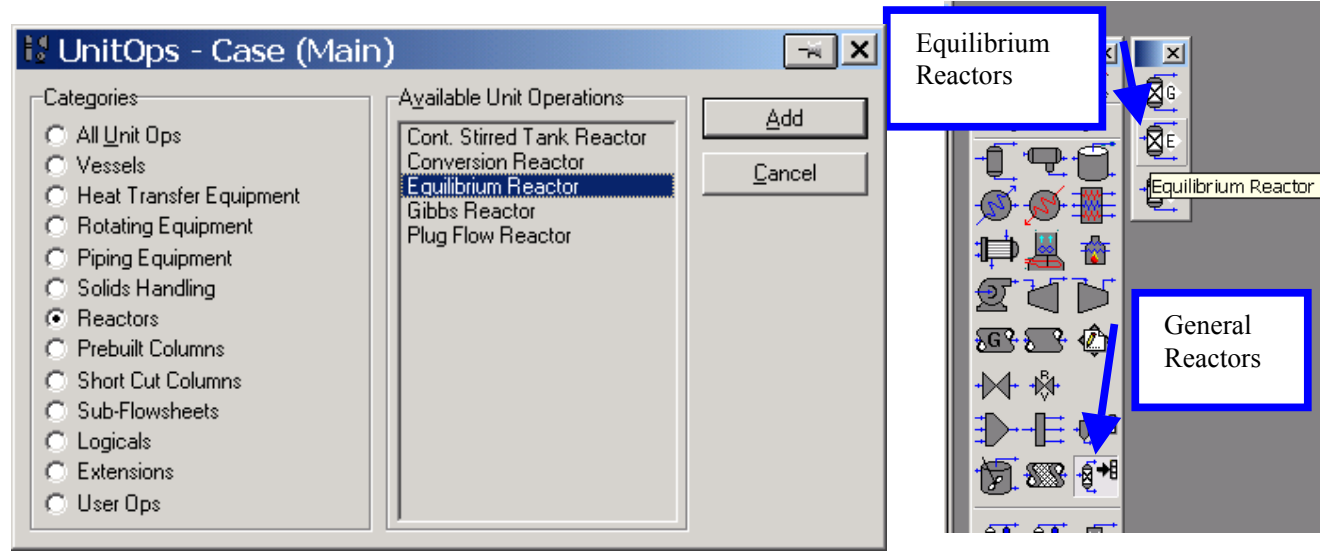

61. Label the streams as shown

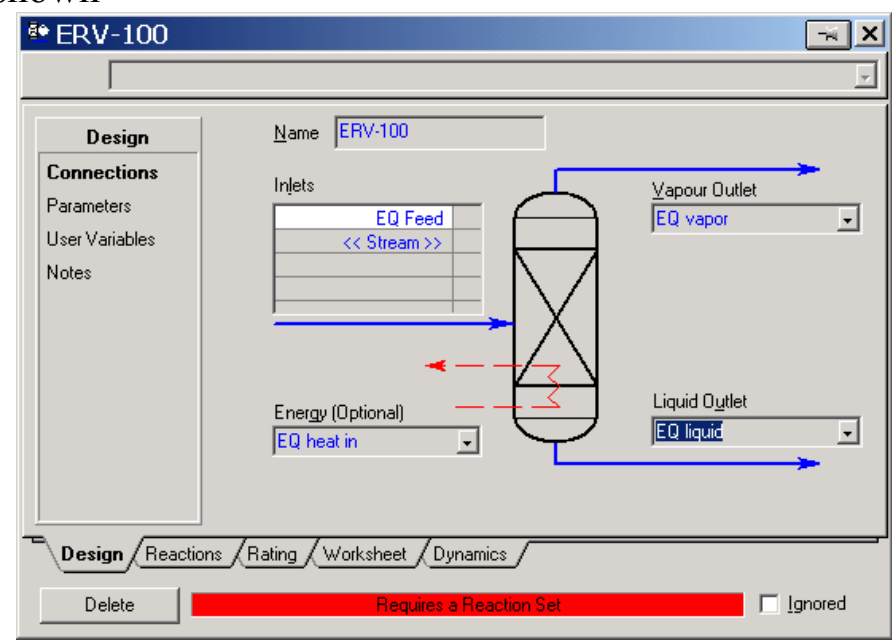

62. Notice that in Red is a warning that it needs a reaction set. Let's see if it likes the one we already have. Pull in the reaction being used by the PFR. Whoops! It didn't like this one! Equilibrium reactors can only have equilibrium reactions. We will have to create a new one.

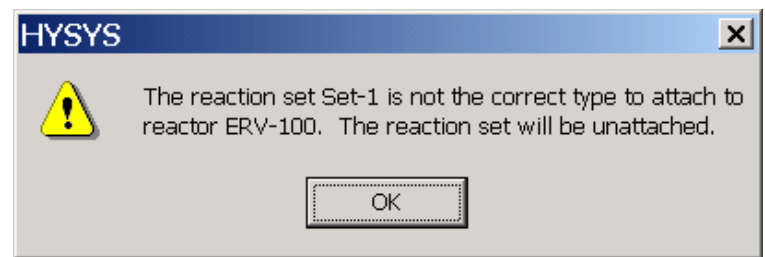

63. Click on the Erlenmeyer flask or choose Simulation, Enter Basis Environment.

64. Add a new reaction.

65. Go to the Library tab and choose the library reaction. Wow it was in there all the time!
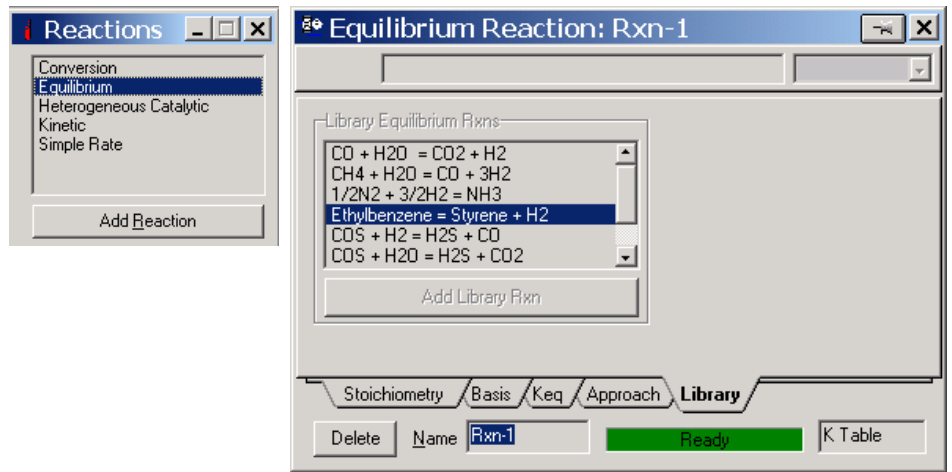

Proceedings of the 2002 American Society for Engineering Education Annual Conference \& Exposition Copyright (C) 2002, American Society for Engineering Education 
66. Look at the Keq page.A plot of the data given in the HYSYS table and the equation that HYSYS uses to fit the data is given below. This comparison shows that the hand calculations and the HYSYS stored values are in good agreement with each other in the temperature range of $500 \leq T \leq 920 \mathrm{~K}$. Above $920 \mathrm{~K}$ the values of $\mathrm{K}$ begin to deviate from each other.

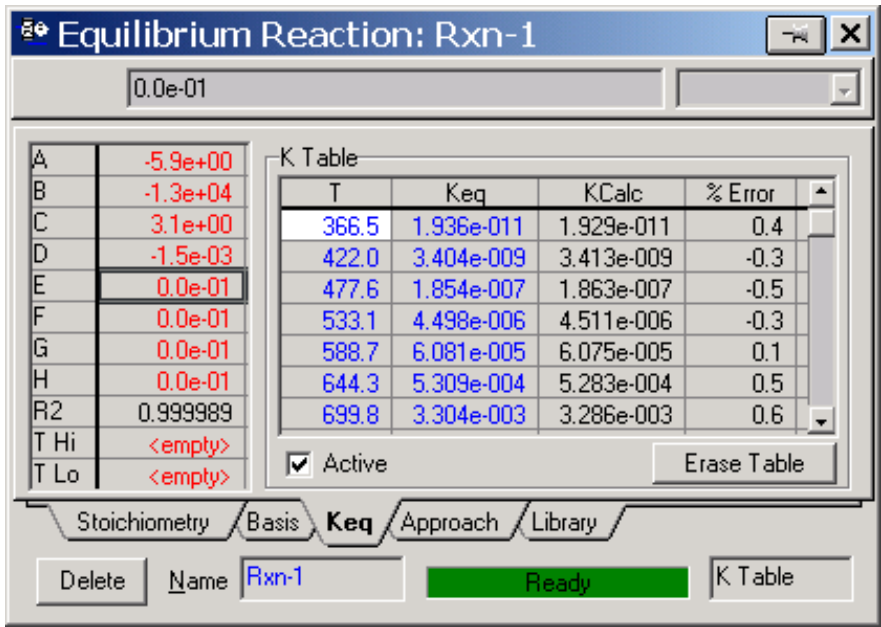

\section{Comparison of HYSYS Predictions with Hand Calculations}

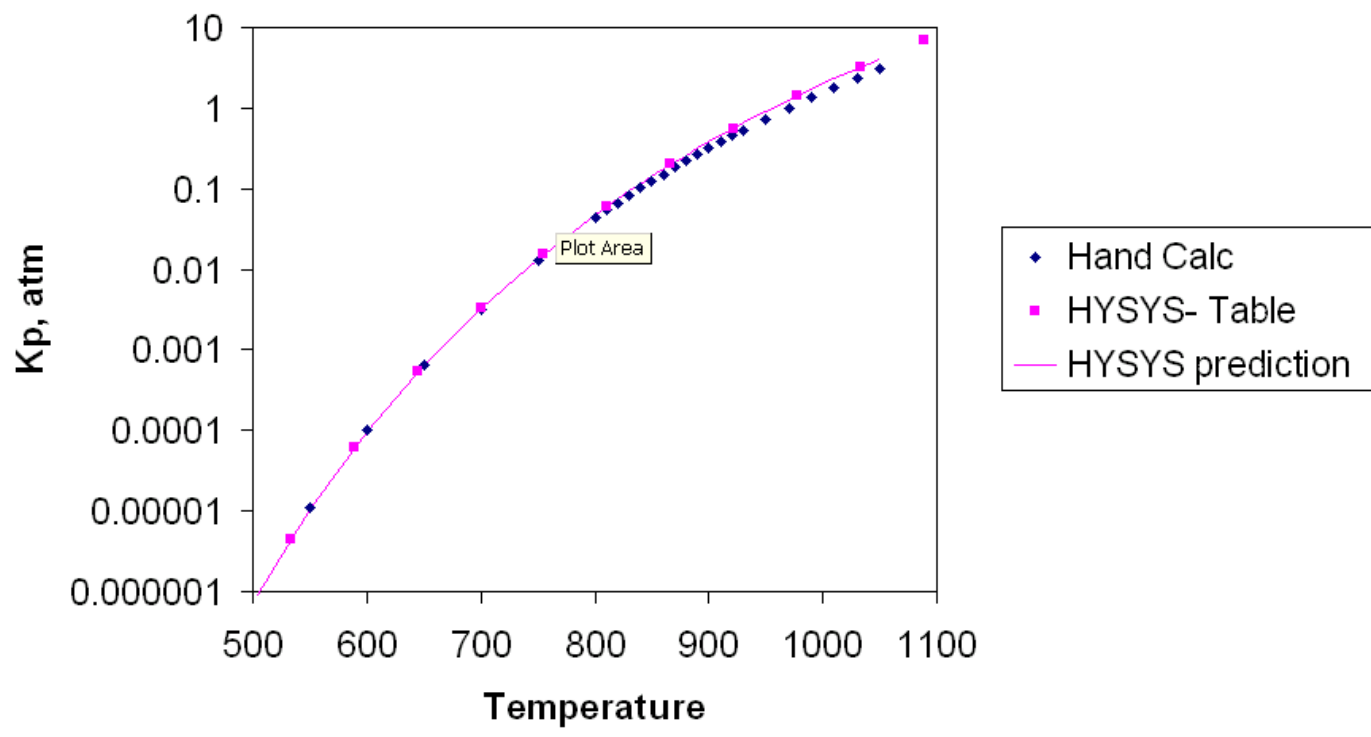

67. Attach the equilibrium reaction to a new reaction set starting with step 21 on page 14 . When finished return to the next step

68. Return to the reactor using the green arrow and bring in the new reaction set to the equilibrium reactor. Now you see why you need in come cases more than one reaction set. Another reason is that you may want one set of reactions for a dehydrogenation reactor and then a separate set for an oxidation reactor.

69. Bring in the equilibrium reaction set into the reactor

70. Now specify the feed stream and the temperature of one outlet stream. Examine the following 2 conditions from your PFR

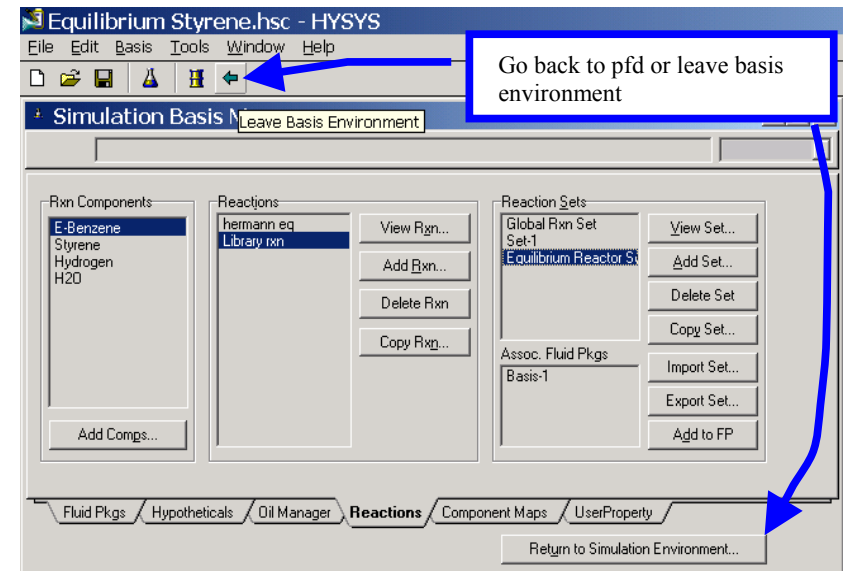
simulations at $880 \mathrm{~K}$ and 1.378 bar with: 


\begin{tabular}{|cl|l|l|}
\hline \multicolumn{2}{|c|}{ Cases } & HYSYS Library & Hand Calculations \\
\hline \multirow{2}{*}{70.1.} & $F_{E B_{0}}=152.2 \mathrm{~mol} / \mathrm{s}$ & $\chi=40.03$ & $\chi=37.4$ \\
& $F_{\text {steam }}=0$ & $K=0.2595$ & $K=0.221$ \\
\hline 70.2. & $F_{E B_{0}}=152.2 \mathrm{~mol} / \mathrm{s}$ & $\chi=74.95$ & $\chi=72.5$ \\
& $F_{\text {steam }}=1522 \mathrm{~mol} / \mathrm{s}$ & $K=0.2595$ & $K=0.2595$ \\
\hline
\end{tabular}

71. Now add the values from your hand calculation into the equilibrium reactor. Go to view reaction and enter these values within the reactor's reaction tab. Within the equilibrium reaction choose the basis tab and select the $\operatorname{Ln}(\mathrm{Keq})$ Equation:

72. Next enter the following table of coefficients for this equation

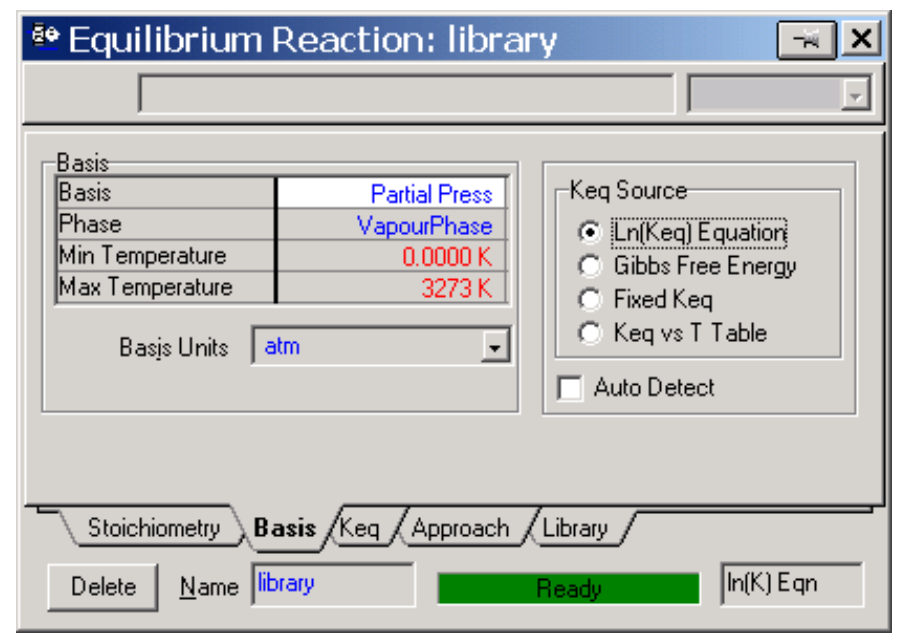

\begin{tabular}{lc}
\hline & Coefficients \\
\hline $\mathrm{A}$ & -13.2117277 \\
$\mathrm{~B}$ & -13122.4699 \\
$\mathrm{C}$ & 4.353627619 \\
$\mathrm{D}$ & -0.00329709 \\
\hline
\end{tabular}

73. Now rerun the above cases. This will predict the PFR equilibrium values given in the table below.

\begin{tabular}{|cl|l|l|l|}
\hline \multicolumn{2}{|c|}{ Cases } & $\begin{array}{l}\text { HYSYS } \\
\text { Library }\end{array}$ & $\begin{array}{l}\text { Hand } \\
\text { Calculations }\end{array}$ & $\begin{array}{l}\text { Regression } \\
\text { from Hand } \\
\text { Calculations }\end{array}$ \\
\hline 73.1. & $F_{E B_{0}}=152.2 \mathrm{~mol} / \mathrm{s}$ & $\chi=40.03$ & $\chi=37.4$ & $\chi=37.4$ \\
& $F_{\text {steam }}=0$ & $K=0.2595$ & $K=0.221$ & $K=0.221$ \\
\hline 73.2. & $F_{E B_{0}}=152.2 \mathrm{~mol} / \mathrm{s}$ & $\chi=74.95$ & $\chi=72.5$ & $\chi=72.5$ \\
& $F_{\text {steam }}=1522 \mathrm{~mol} / \mathrm{s}$ & $K=0.2595$ & $K=0.2595$ & $K=0.221$ \\
\hline
\end{tabular}

Notice that with the PFR you need a large volume or mass of catalyst to achieve these equilibrium values. You previously tried this with your PFR and you came close to these above values. In step 56 on page 18 your PFR values were 37.42 and $72.5 \%$.

74. Which values are correct? Since, no reference is given by HYSYS to the library reaction and you know the source of the hand calculations ${ }^{19}$ you should trust your hand calculations. 
Minimization of Gibbs Free Energy

75. Go back to the reaction screen and choose the Gibbs Free Energy radio button.

76. Wow! Now you get $100 \%$ conversion. Please note that this problem does not exist in HYSYS version 3.0 and later. Why is this and what is going on? If you change the reactor temperature to about $510 \mathrm{~K}$ then you obtain $37 \%$ conversion for the case with no water. In this calculation, the equilibrium constant is determined from the Ideal

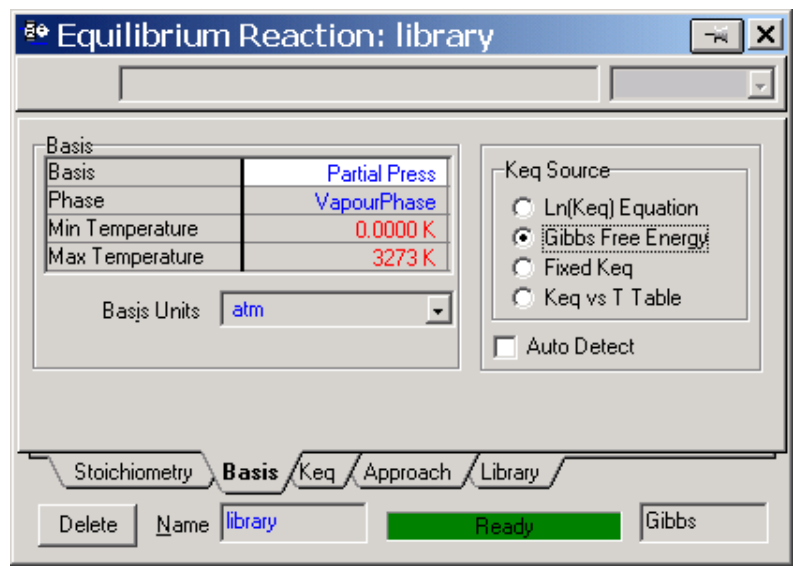
Gas Gibbs Free Energy Coefficients in the HYSYS library.

77. Examine these values.

77.1. Enter the basis environment.

77.2. View the property package

77.3. Select styrene and view the component

77.4. Choose the temperature dependent tab:

Tdep. Notice that the default values for the Ideal Gas Gibbs Free Energy Coefficients in the HYSYS library are not temperature dependent. It

Fluid Package: Basis-1

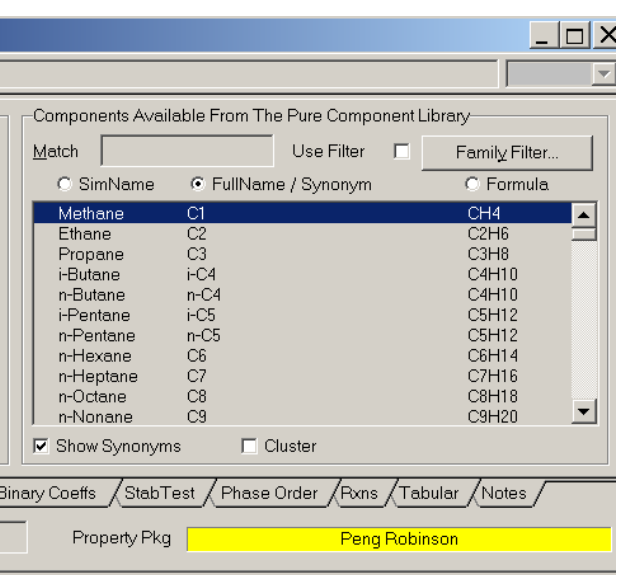

is a constant. This is incorrect. The correct values are given in the cloned component created by Aaron

Pollock of

Hyprotech

Technical

Support. ${ }^{20}$ This

is a clear example

of why you can't

trust a process

simulator to give

you the correct

values. You need

to investigate

what it is doing.

Please note that

this problem

does not exist in

HYSYS version

3.0 and later.
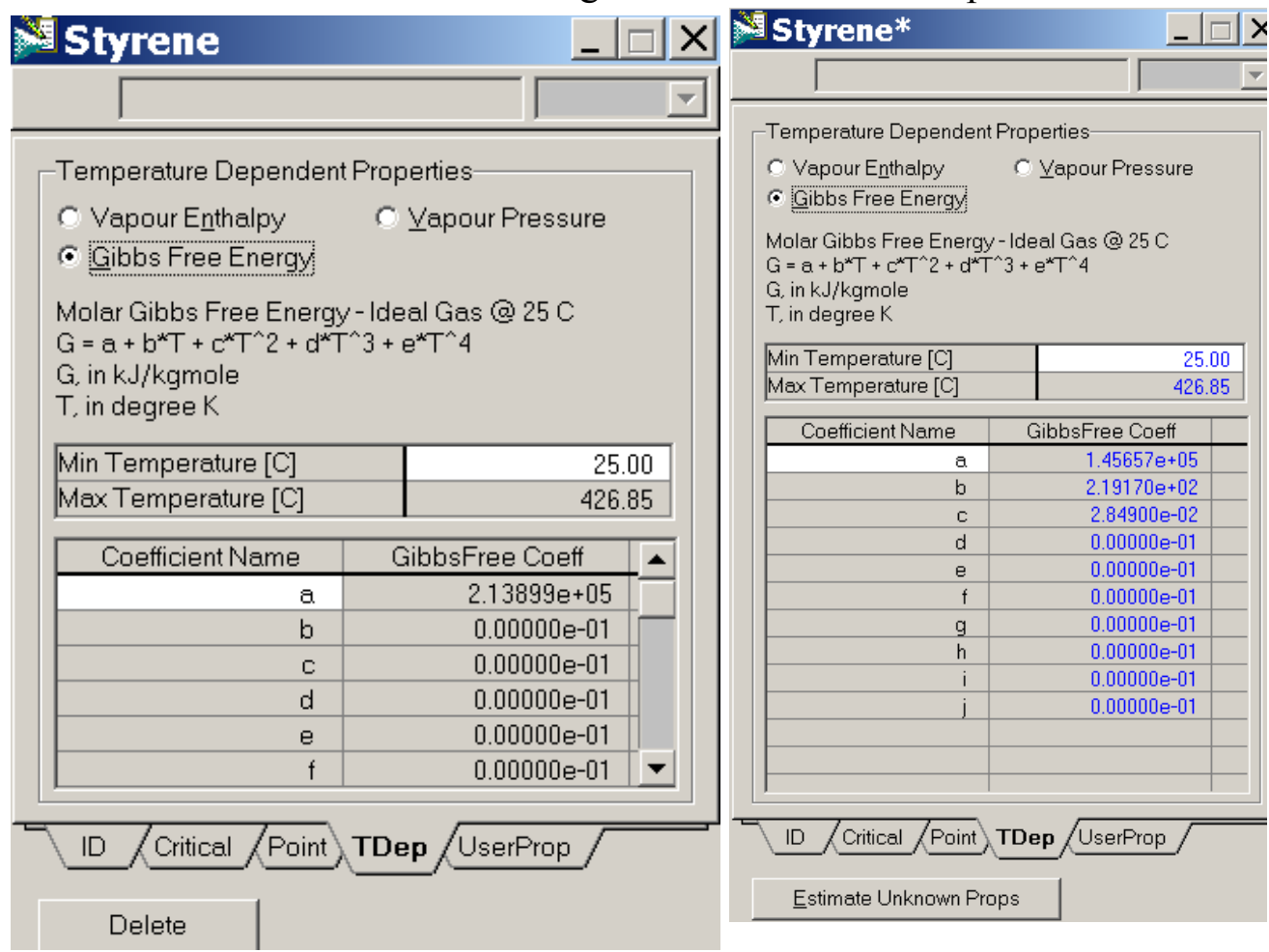

Proceedings of the 2002 American Society for Engineering Education Annual Conference \& Exposition

Copyright C 2002, American Society for Engineering Education 
Gibbs Reactor

78. Now install a $3^{\text {rd }}$ reactor called a Gibbs Reactor and label the streams and define the feed and outlet temperature of the streams.

79. Put in the conditions given in step 70 on page 22 above. Notice that the same result as an equilibrium reactor using the gibbs free energy results. The only difference for this reactor is that you did not need to specify the stoichiometry of the reaction.

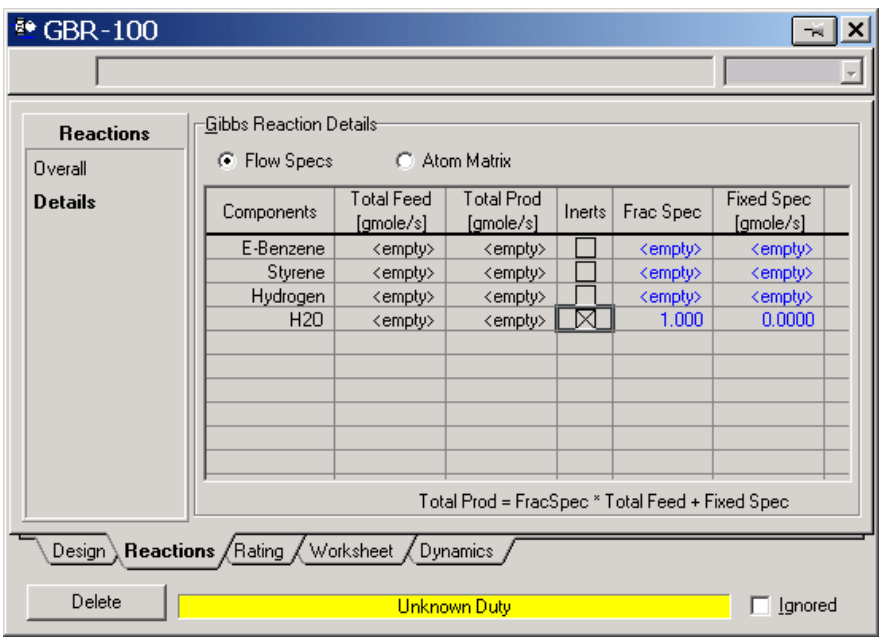

80. At the end of this exercise submit
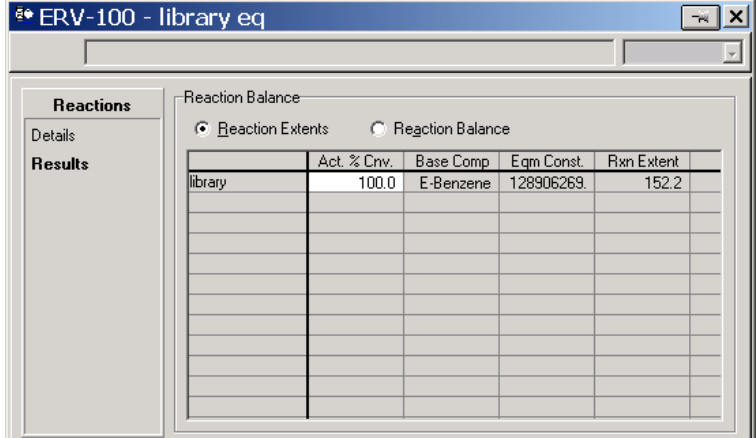

Design Reactions Rating/Worksheet Dynamics
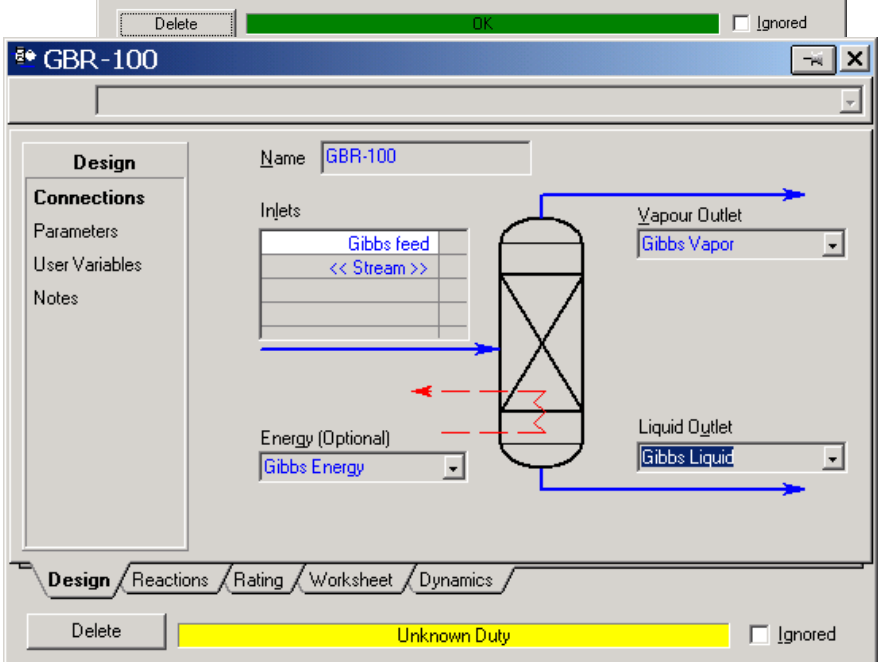

a) Graphs from PFR

i) the effect of temperature and pressure on equilibrium conversion (see step 58)

ii) the effect of the molar flow of steam and temperature on equilibrium conversion at a fixed pressure and ethylbenzene flowrate (see step 59).

iii) Short summary of the effect of $T, P$ and steam flow on equilibrium conversion.

b) Pfd of the three reactors

\section{References:}

${ }^{1}$ Seider, Warren D., J. D. Seader, Daniel R. Lewin, Process Design Principles: Synthesis, Analysis and Evaluation, John Wiley and Sons, 1999

${ }^{2}$ GAMS see http://www.che.utexas.edu/cache/newsletters/fall97_art2.pdf

${ }^{3}$ Aspen Technology, Inc

${ }^{4}$ Lewin, D. R., W. D. Seider, J. D. Seader, E. Dassau, J. Golbert, G. Zaiats, D. Schweitzer, D. Goldberg, Using Process Simulators in ChemicalEngineering: A multimedia Guide for the Core Curriculum, John Wiley \& Sons, Inc., New York, 2001.

${ }^{5}$ Lewin, D. R. W. D. Seider, JD Seader, "Teaching Process Design: An Integrated Approach”, AIChE Paper 63d, 2000 AIChE Annual Meeting, Los Angeles.

${ }^{6}$ L. G. Richards and S. Carlson-Skalak, "Faculty Reactions to Teaching Engineering Design to First Year Students", Journal of Engineering Education, Vol. 86, No. 3, pp. 233-240, July 1997.

7 ASME, Innovations in Engineering Design Education: Resource Guide, American Society of Mechanical Engineers, New York, 1993. 
${ }^{8}$ R. H. King, T. E. Parker, T. P. Grover, J. P. Gosink, N. T. Middleton, "A Multidisciplinary Engineering Laboratory Course", Journal of Engineering Education, Vol. 88, No. 3, pp. 311-316, July 1999.

${ }^{9}$ S. S. Courter, S. B. Millar and L. Lyons, "From the Student's Point of View: Experiences in a Freshman Engineering Design Course", Journal of Engineering Education, Vol. 87, No. 3, pp. 283-288, July 1998.

10 "Engineering Criteria 2000: Criteria for Accrediting Programs in Engineering in the United States," 3rd Ed., Engineering Accreditation Commission, Accreditation Board for Engineering and Technology, Inc., Baltimore, MD, 1999, http://www.abet.org/eac/eac.htm.

${ }^{11}$ Phillip C. Wankat, Equilibrium Staged Separations, Elsevier, 1988.

${ }^{12}$ Michael A. Henson and Yougchun Zhang, "Integration pf Commercial Dynamic Simulators into the Undergraduate Process Control Curriculum". Proceedings of the AIChE Annual Meeting, Los Angeles, CA, Nov. 2000.

${ }^{13}$ David E. Clough, “Using Process Simulators with Dynamics/Control Capabilities to Teach Unit and Plantwide Control Strategies". Proceedings of the AIChE Annual Meeting, Los Angeles, CA, Nov. 2000.

${ }^{14}$ A. S. Foss, K. R. Guerts, P. J. Goodeve, K. D. Dahm, G. Stephanopoulos, J. Bieszczad, A. Koulouris, "A Phenomena-Oriented Environment for Teaching Process Modeling: Novel Modeling Software and Its Use in Problem Solving," Chemical Engineering Education, Fall 1999.

${ }^{15}$ Fogler, H. Scott, Elements of Chemical Reaction Engineering, $3^{\text {rd }}$ Ed., Prentice Hall PTR, Upper Saddle River, NJ, 1999.

${ }^{16}$ R. P. Hesketh, "Incorporating Reactor Design Projects into the Course," Paper 149e, 1999 AIChE Annual Meeting, Dallas, TX, 31 October - 5 November 1999.

${ }^{17}$ Hermann, Ch.; Quicker, P.; Dittmeyer, R., "Mathematical simulation of catalytic dehydrogenation of ethylbenzene to styrene in a composite palladium membrane reactor." J. Membr. Sci. (1997), 136(1-2), 161-172.

${ }^{18}$ Fogler, H. S. Elements of Chemical Reaction Engineering, 3rd Ed., by, Prentice Hall PTR, Englewood Cliffs, NJ (1999).

19 "Thermodynamics Source Database" by Thermodynamics Research Center, NIST Boulder Laboratories, M. Frenkel director, in NIST Chemistry WebBook, NIST Standard Reference Database Number 69, Eds. P.J. Linstrom and W.G. Mallard, July 2001, National Institute of Standards and Technology, Gaithersburg MD, 20899

(http://webbook.nist.gov).

${ }^{20}$ Yaws, C.L. and Chiang, P.Y., "Find Favorable Reactions Faster", Hydrocarbon Processing, November 1988, pg 81-84.

\section{BIOGRAPHICAL INFORMATION}

Stephanie Farrell is Associate Professor of Chemical Engineering at Rowan University. She received her B.S. in 1986 from the University of Pennsylvania, her MS in 1992 from Stevens Institute of Technology, and her Ph.D. in 1996 from New Jersey Institute of Technology. Prior to joining Rowan in September 1998, she was a faculty member in Chemical Engineering at Louisiana Tech University. Stephanie's has research expertise in the field of drug delivery, and integrates pharmaceutical and biomedical topics and experiments into the chemical engineering curriculum. Stephanie won the 2000 Dow Outstanding Young Faculty Award, the 2001 Joseph J. Martin Award, and the 2002 Ray W. Fahien Award.

Robert Hesketh is a highly motivated professor in both undergraduate and graduate education and has received 9 education and 2 research awards, including ASEE's 1999 Ray W. Fahien Award. He has made major contributions in laboratory methods that demonstrate chemical engineering practice and principles. These highly visual and effective experiments, the most notable using the vehicle of a coffeemaker, are used to introduce engineering design and science to university and pre-college students. He has developed over 20 experiments employed throughout the curriculum at Rowan University. These experiments range from small scale coffee experiments to $25 \mathrm{ft}$ distillation column experiments. His work has been presented at national meetings, workshops and published in journals and proceedings and his experiments are being used in over 15 institutions. He has attracted over 2 million dollars in external funding for research and educational activities.

Proceedings of the 2002 American Society for Engineering Education Annual Conference \& Exposition Copyright (C) 2002, American Society for Engineering Education 
C. Stewart Slater is Professor and Chair of Chemical Engineering at Rowan University. He received his B.S., M.S. and Ph.D. from Rutgers University. Prior to joining Rowan he was Professor of Chemical Engineering at Manhattan College where he was active in chemical engineering curriculum development and established a laboratory for advanced separation processes with the support of the National Science Foundation and industry. Dr. Slater's research and teaching interests are in separation and purification technology, laboratory development, and investigating novel processes for interdisciplinary fields such as biotechnology and environmental engineering. He has authored over 70 papers and several book chapters. Dr. Slater has been active in ASEE, having served as Program Chair and Director of the Chemical Engineering Division and has held every office in the DELOS Division. Dr. Slater has received numerous national awards including the 1999 and 1998 Joseph J. Martin Award, 1999 Chester Carslon Award, 1996 George Westinghouse Award, 1992 John Fluke Award, 1992 DELOS Best Paper Award and 1989 Dow Outstanding Young Faculty Award. 